San Jose State University

SJSU ScholarWorks

Master's Theses

Master's Theses and Graduate Research

Spring 2015

\title{
Using Satellite Remote Sensing, Field Observations and WRF/ Single-Layer Urban Canopy Model Simulation to Analyze the Oklahoma City UHI Effect
}

Hengyue Zhang

San Jose State University

Follow this and additional works at: https://scholarworks.sjsu.edu/etd_theses

\section{Recommended Citation}

Zhang, Hengyue, "Using Satellite Remote Sensing, Field Observations and WRF/Single-Layer Urban Canopy Model Simulation to Analyze the Oklahoma City UHI Effect" (2015). Master's Theses. 4567. DOI: https://doi.org/10.31979/etd.x5js-w4em

https://scholarworks.sjsu.edu/etd_theses/4567

This Thesis is brought to you for free and open access by the Master's Theses and Graduate Research at SJSU ScholarWorks. It has been accepted for inclusion in Master's Theses by an authorized administrator of SJSU ScholarWorks. For more information, please contact scholarworks@sjsu.edu. 
USING SATELLITE REMOTE SENSING, FIELD OBSERVATIONS AND WRF/SINGLE-LAYER URBAN CANOPY MODEL SIMULATION TO ANALYZE THE OKLAHOMA CITY UHI EFFECT

\author{
A Thesis \\ Presented to \\ The Faculty of the Department of Meteorology and Climate Science \\ San José State University
}

In Partial Fulfillment

of the Requirements for the Degree

Masters of Science

by

Hengyue Zhang

May 2015 
(C) 2015

Hengyue Zhang

ALL RIGHTS RESERVED 
The Designated Thesis Committee Approves the Thesis Titled

USING SATELLITE REMOTE SENSING, FIELD OBSERVATIONS AND WRF/SINGLE-LAYER URBAN CANOPY MODEL SIMULATION TO ANALYZE THE OKLAHOMA CITY UHI EFFECT

\author{
by \\ Hengyue Zhang \\ APPROVED FOR THE DEPARTMENT OF METEORLOGY \\ AND CLIMATE SCIENCE
}

SAN JOSÉ STATE UNIVERSITY

May 2015

$\begin{array}{ll}\text { Dr. Menglin S. Jin } & \text { Department of Meteorology and Climate Science } \\ \text { Dr. Martin J. Leach } & \text { Department of Meteorology and Climate Science } \\ \text { Dr. Craig B. Clements } & \text { Department of Meteorology and Climate Science }\end{array}$ 


\title{
ABSTRACT \\ USING SATELLITE REMOTE SENSING, FIELD OBSERVATIONS AND WRF/SINGLE-LAYER URBAN CANOPY MODEL SIMULATION TO ANALYZE THE OKLAHOMA CITY UHI EFFECT
}

\author{
by Hengyue Zhang
}

The Urban Heat Island (UHI) was investigated using satellite data, ground observations, and simulations with an Urban Canopy Parameterization in a numerical weather prediction model. Satellite-observed surface skin temperatures at Xi'an City and Oklahoma City (OKC) were analyzed to compare the UHI intensity for the two inland cities. A larger population density and larger building density in Xi' an City creates a stronger skin-level UHI effect. However, ground observed 2-m surface air temperature $\left(\mathrm{T}_{\text {air }}\right)$ data showed an urban cooling island (UCI) effect that occurred over an urban region in OKC during the daytime of July 19, 2003.

The sensitivity and accuracy of an Urban Canopy Model were evaluated by comparing simulation results between the urban and rural areas of OKC. The model reproduced skin temperature differences between the rural and urban area and reproduced a UCI effect in OKC. Furthermore, the Weather Research and Forecasting (WRF)/Noah/Single-Layer Urban Canopy Model (SLUCM) simulations were also compared with ground observations, including wind speeds, wind directions, and energy fluxes. Although the WRF/SLCUM model failed to simulate these variables accurately, it reproduced the diurnal variations of surface temperatures, wind speeds, wind directions and energy fluxes reasonably well. 


\section{ACKNOWLEDGEMENTS}

Many thanks to my advisor and mentor, Dr. Menglin Jin, her generous guidance made it possible for me to complete my thesis. I would like to address special thanks to her continuous support, advice and endless patience in improving my writing. Dr. Jin was always available to help me and constantly provided feedback on my work. I sincerely thank the other members of my committee: Dr. Martin Leach and Dr. Craig Clements, for their guidance and encouragement, for their kind words and suggestions.

I would like to thank my close friends Yu Li, Shirin Zarrinkamar, Diana Centeno, and Henry Bartholomew, for their willingness and patience to help me whenever I need assistance. They made my graduate student life more fun and meaningful.

Finally, most of all I want to thank my family in China. Words cannot describe how much they've supported me and gave me strength to live and study in a foreign country far away from home. Without them, it wouldn't have been possible for me to accomplish my work.

In this paper, IDL, MATLAB, GrADS, NCL and NCAR Graphics were used to create most of the figures (Figure 6 - Figure 24). 


\section{TABLE OF CONTENTS}

LIST OF FIGURES....................................................... viii

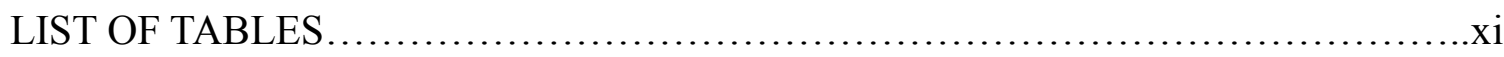

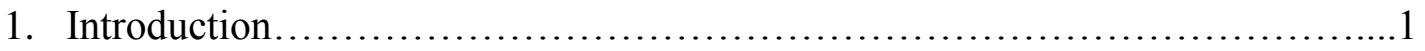

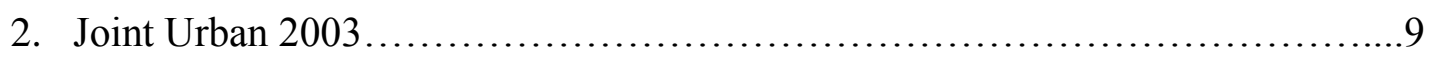

3. Data and Methods...................................................... 10

3.1 Satellite Observation ...............................................10

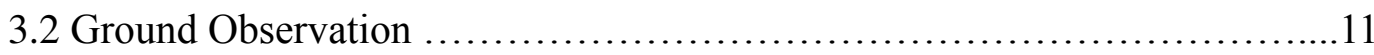

3.3 WRF/Single-Layer Urban Canopy Model (SLUCM) Simulation..............14

4. Results.......................................................... 19

4.1 Satellite Observation Analysis......................................19

4.2 Ground Observation Analysis......................................27

4.3 WRF/Single-Layer Urban Canopy Model (SLUCM) Simulation Analysis...34

5. Conclusions......................................................50

References............................................................... 54

APPENDIX: ACRONYMS .................................................... 58 


\section{LIST OF FIGURES}

Figure 1: Locations of Xi'an City (http://a4.att.hudong.com/56/71/1430000093266412 8157715689635.jpg) and $\mathrm{OKC}$

(http://gdscseusa.net/upload/userfile/2010/03/12676954572021908495.gif)on their

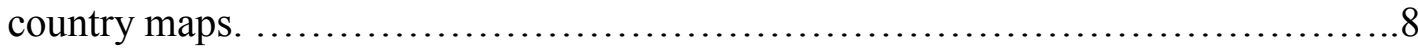

Figure 2: Overview of the PNNL Meteorological Station and HOBO locations. The light green pentagons are HOBOs, while the dark green pentagons are meteorological stations. Allwine and Flaherty 2006, CCourtesy of Battelle memorial Institute, operating contractor. From the Pacific Northwest National Laboratory for the U.S. Department of Energy. 12

Figure 3: Overview of the Atmospheric Turbulence and Diffusion Division (ATDD) flux site locations. Hanna et al. 2011, CAmerican Meteorological Society ..... 13

Figure 4: Single-Layer Urban Canopy Model. Ta: air temperature at reference height Za. $\mathrm{T}_{\mathrm{R}}$ : building roof temperature. $\mathrm{T}_{\mathrm{W}}$ : building wall temperature. $\mathrm{T}_{\mathrm{G}}$ : road temperature. $\mathrm{T}_{\mathrm{S}}$ : temp defined at $\mathrm{Z}_{\mathrm{T}}+\mathrm{d}$. $\mathrm{H}$ : sensible heat exchange at reference height. Ha: sensible heat flux from the canyon space to atmosphere. $\mathrm{H}_{\mathrm{W}}$ : sensible heat flux from wall to canyon space. $\mathrm{H}_{\mathrm{G}}$ : sensible heat flux from road to canyon space. $\mathrm{H}_{\mathrm{R}}$ : sensible heat flux from roof to the atmosphere. Kusaka et al. 2001, (CSpringer. 14

Figure 5: Radiation of the single-layer urban canopy model. $\mathrm{S}_{\mathrm{D}}$ : direct solar radiation on a horizontal surface. w: normalized road width. h: normalized building height. $\mathrm{w}+\mathrm{r}=1$, where $\mathrm{r}$ is the normalized roof width. $1_{\text {shadow: }}$ normalized shadow length on the road. $\theta z$ : solar zenith angle. Kusaka et al. 2001, (CSpringer 15

Figure 6: Three nesting domains with 25,5 , and $1 \mathrm{~km}$ grid spacing in WRF simulation.

Figure 7: MODIS land surface cover type of (a) Oklahoma and (c) Xi'an. Land surface cover type is given in Table 5 . Land cover $=13$ denotes urban area (red mapped areas). Locations of OKC and Xi'an City are marked in the figures. MODIS monthly daytime land surface temperature (expressed in $\mathrm{K}$ ) was recorded in June 2008 by Terra at 10:30 local time for (b) OKC in June 2008 and (d) Xi'an City...... 22

Figure 8: (a) OKC monthly averaged daytime skin temperature (2001-2008), (b) OKC monthly averaged daytime skin temperature difference (urban - nonurban), (c) OKC monthly averaged nighttime skin temperature (2001-2008), (d) OKC monthly averaged nighttime skin temperature difference (urban - nonurban). 24 
Figure 9: (a) Xi'an City monthly averaged daytime skin temperature (2001-2008), (b) Xi'an City monthly averaged daytime skin temperature difference (urban nonurban), (c) Xi'an City monthly averaged nighttime skin temperature (20012008), (d) Xi'an City monthly averaged nighttime skin temperature difference (urban - nonurban). 25

Figure 10: (a) Xi'an City and $\mathrm{OKC}$ monthly averaged daytime skin temperature difference (urban - nonurban), (b) Xi' an City and OKC monthly averaged nighttime skin temperature difference (urban - nonurban) 26

Figure 11: The Delta $T$ values for 2-meter air temperatures for each station in (a) $\mathrm{X}$ direction and (b) Y-direction. 29

Figure 12: 24-h diurnal variation of 2-meter air temperatures from PNNL HOBO station No. 22, station No. 25, and station No. 28. 30

Figure 13: Map of locations of the PNNL HOBO station No. 22, station No. 25, and station No. 28.

Figure 14: ATDD flux site $\mathrm{C}$ observed 24-h diurnal variation of soil temperature (C) at $32 \mathrm{~cm}$ and $64 \mathrm{~cm}$ in $\mathrm{OKC}$ 33

Figure 15: ATDD flux site $\mathrm{C}$ observed 24-h diurnal variation of sensible heat flux (W m2) in $\mathrm{OKC}$. 33

Figure 16: ATDD flux site $\mathrm{C}$ observed 24-h diurnal variation of wind speed and wind

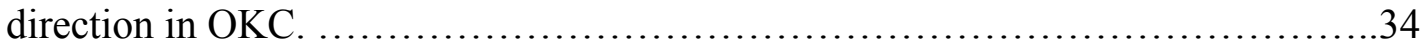

Figure 17: Land use maps for OKC from (a) National Land Cover Database 2001 and (b) WRF/SLUCM simulation. 36

Figure 18: (a) WRF simulated surface temperature difference at 18 UTC, July 19, 2003, in $\mathrm{OKC}$ for $\mathrm{T}_{\text {skin }}$ difference (sensitive run - control run). (b) WRF simulated surface temperature difference at $18 \mathrm{UTC}$, July 19, 2003 in OKC for 2-meter $\mathrm{T}_{\text {air }}$ difference (sensitive run - control run) Temperatures are expressed in $\mathrm{K}$, and $\mathrm{OKC}$ is represented as the rectangle area 39

Figure 19: (a) $\mathrm{T}_{\text {skin }}$ (sensitive run vs. control run) in urban regions in $\mathrm{OKC}$, with the green curve representing the simulation of the control run, and the black curve representing the simulation of the sensitive run. (b) $\mathrm{T}_{\text {skin }}$ difference (sensitive run control run) in urban regions in $\mathrm{OKC}$.

Figure 20: (a) the WRF/SLUCM-simulated $\mathrm{T}_{\text {skin }}$ (urban vs. rural) in $\mathrm{OKC}$, with the green curve representing the $\mathrm{T}_{\text {skin }}$ over $\mathrm{OKC}$ urban area, and the black curve representing 
the $\mathrm{T}_{\text {skin }}$ over its rural area. (b) the SLUCM-simulated $\mathrm{T}_{\text {skin }}$ difference (urban - rural) in $\mathrm{OKC}$

Figure 21: (a) the WRF/SLUCM-simulated wind speed (urban vs. rural) in OKC. The black line shows the wind speeds over the urban area, while the green line shows the wind speeds over the rural area. (b) the WRF/SLUCM-simulated wind direction (urban vs. rural) in OKC. The black line shows the wind directions over the urban area, and the green line shows the wind directions over rural area. 45

Figure 22: WRF-simulated TSK, $T_{2}$ and ground-observed $T_{2}$. The red solid line represents the model-simulated TSK with SLUCM, the black solid line represents the model-simulated TSK without SLUCM, the red dashed line shows the modelsimulated $\mathrm{T}_{2}$ with SLUCM, the black dashed line shows the model-simulated $\mathrm{T}_{2}$ without SLUCM, and the blue line represents the ground-observed $\mathrm{T}_{2}$ from PNNL HOBO station 9. 46

Figure 23: (a) the WRF-simulated downward shortwave radiation and ground-observed downward shortwave radiation in OKC (b): the WRF-simulated net radiation and ground-observed net radiation in $\mathrm{OKC}$

Figure 24: 24-h diurnal variation of WRF/SLUCM simulated and ground observed (a) wind speed $(\mathrm{m} / \mathrm{s}),(\mathrm{b})$ wind direction (degree $0,360=$ North) in OKC. 50 


\section{LIST OF TABLES}

1. Atmospheric input to the single-layer urban canopy model....................16

2. Atmospheric output from the single-layer urban canopy model................16

3. Surface parameters and canyon dimensions........................... 17

4. Physical constants used in the models................................ 17

5. MODIS land cover types.......................................... 21

6. USGS 24 -category land use categories............................... 37 


\section{Introduction}

Planet Earth is a physical system that conserves energy, including the incoming energy gains and the losses of the outgoing energy. For an equilibrium climate, the global mean incoming absorbed solar radiation balances the outgoing long-wave radiation. In general, in the Earth's system, $19 \%$ of the incoming solar radiation is absorbed in the atmosphere, $30 \%$ is lost to space, and $51 \%$ is absorbed at the surface. This last component of the incoming radiation, along with the outgoing sensible heat flux, is the main contributor to the surface skin temperature (Trenberth et al. 2009). However, urbanization and human influences are changing the composition of the atmosphere leading to an imbalance in the energy fluxes.

The aim of the present study is to better understand the surface temperature changes related to the urban system. Surface temperature can be simply explained as the perceived "surface" heat at a particular location on Earth. From the satellite perspective, the "surface" is defined as whatever ground-level information is transmitted through the atmosphere. Thus, surface temperatures retrieved from satellite observations are called "surface skin temperature ( $\left.\mathrm{T}_{\text {skin }}\right)$ " (Jin et al. 1997). However, the air temperature cited in daily weather reports, defined as the surface air temperature $\left(\mathrm{T}_{\text {air }}\right)$ and observed in an 
aspirated weather shelter positioned at 2-m height above the surface, differs from surface skin temperature.

Urbanization usually leads to significant changes in the atmospheric and surface properties, creating an urban micro-climate (Landsberg 1981; Oke 1982). This includes the Urban Heat Island (UHI) effect: a phenomenon in which the prevailing surface temperature in an urban area is usually higher than the surface temperature in an adjacent rural area, with greater temperature difference during nighttime than during daytime (Landsberg 1981; Oke 1987; Jin et al. 2005). The impact of UHI is increasingly becoming a global concern, as around half of the world's human population lives in urban areas and the population migration from rural to urban areas continues (Annez and Buckley 2009). The UHI effect affects the weather in urban regions by, for example, modifying surface skin temperature and precipitation (Jin 2012), and thus affects human health. For example, an increased frequency of heat waves in urban regions leads to heat-related illness and even death (Basara et al. 2008). Therefore, in recent years, numerous studies on UHI have been carried out, focusing on human health.

The main physical mechanisms of the UHI are well documented. For example, the heat capacity of materials used in urban constructions is much greater than that of the original vegetation in the forests and other natural features. As a result, urban structures 
that absorb a large amount of thermal energy during daytime slowly emit the stored heat energy during late afternoon and nighttime. Evapotranspiration, a process that converts liquid-water to water vapor as a natural cooling mechanism, is limited on urban waterproof surfaces. The presence of tall buildings in urban regions causes the surface roughness to vary; thus, buildings lift the air, enhancing convection. Furthermore, buildings often modify the original airflow direction, trap aerosols, thus increase pollution in the urban system and degrade air quality (Janković and Hebbert 2012). Urban construction creates an urban "canopy" geometry, reducing the surface albedo and altering the emissivity in urban regions (Jin et al. 2005). Lower albedo means lower solar reflectance, which increases thermal storage in cities. Walls of the buildings extend the effective urban surface, so that more short-wave radiation is absorbed.

Authors of extant studies analyzed the UHI predominantly using three different information sources: ground observations, satellite observations, and model simulations. For example, Montavez et al. (2000) examined the UHI effect of Granada. They examined the evolution of the temperatures over the last century, using data from meteorological stations. Those records revealed an increasing trend in the minimum temperatures and a decreasing trend in the maximum temperatures. Both urban and rural temperatures were compared, and the study findings revealed a stronger UHI effect in 
winter, with maximum difference in the early morning. In their work, Montavez et al. also examined urban geometry. In a more recent study, Hamdi and Van de Vyver (2011) estimated the UHI effect in Brussels by using the surface temperature data from groundbased weather stations and remote sensing. Urban warming was analyzed during the summer months using data from the years 1955 to 2006 . The analyses were based on remote sensing and the results revealed that the growing rate of the urban bias on minimum air temperature is much higher (about 2.5 times more) than that on maximum air temperature. This is consistent with the results based on ground observations for the estimates of urban warming.

The Weather Research and Forecasting (WRF) model was used by Yang et al. (2012) to investigate UHI. The authors studied the urban climate in Nanjing, a large city in eastern China, using a 1-km resolution WRF model coupled with a single-layer Urban Canopy Model. They concluded that the WRF model was suitable for simulation of surface air temperature, relative humidity, and precipitation frequency, although it underestimated the total amount of precipitation in Nanjing. Chen et al. (2004) studied the UHI phenomena over the greater Houston area by using the coupled WRF/LSM/Urban Modeling system simulation. Their aim was to develop a more complex urban canopy model in WRF, with a more detailed description of urban land 
cover types. Salamanca et al. (2010) studied the urban boundary layer using highresolution urban canopy parameters with WRF. By comparing the results from their case study, the authors concluded that a complex urban canopy scheme and detailed urban canopy parameters are needed for the simulation due to the air conditioning at city scale.

The aforementioned early investigations of UHI demonstrate the utility of satellite observations, ground observations, and model simulations for studying the UHI. For example, satellite observations by MODIS are characterized by high spatial and temporal resolution, global coverage, and high quality observations. Therefore, satellite data are useful for studying the land surface climate. Ground observations can provide significant amounts of surface data at a relatively low cost, and can thus be appropriate for studying long-term, large-scale atmospheric changes. The WRF model is a valuable tool for understanding and predicting the effects of future climate change, simulating the meteorological conditions from regional to building scales.

Nevertheless, MODIS observations and similar methods, ground observations, and model simulations all have their limitations. For example, MODIS observations of $\mathrm{T}_{\text {skin }}$ are available only for clear days, since only IR channels are used to retrieve surface temperature; therefore, MODIS cannot detect surface variables through clouds. Similarly, while the air temperature data obtained from ground observations is useful to examine 
long-term and large-scale changes, it may not be suitable for studying regional impacts on the climate change. Finally, WRF simulations are based on a current understanding of the phenomena of interest, which is not necessarily accurate, because climate is a complex system, characterized by numerous uncertainties. In addition, the WRF model may not be able to capture the influences of city structures accurately due to the heterogeneity of urban areas.

Although continued study of UHI helps to understand urban effects on climate, recent research indicates a possible urban cooling island (UCI) effect, where the surface temperature over urban regions is lower than that in surrounding rural regions. The mechanisms implicit in the UCI are presently unclear, and the interactions between urban surface temperature and the aerosol direct effect in particular is poorly understood. It is speculated that the aerosol direct effect reduces surface insolation. Consequently, it has a net cooling effect, reducing urban surface temperature (Jin and Shepherd 2008).

Jin and Shepherd (2008) combined remote sensing with a WRF model sensitivity study on the urban skin temperature reduction via the urban aerosol direct effect over Beijing, New York City, Mexico City, and Moscow. Their findings revealed that, while urban aerosols reduce both the $T_{\text {skin }}$ and the $T_{\text {air }}$, the magnitude of reduction is insufficient to offset the UHI (Jin and Shepherd 2008). Jin et al. (2011) carried out a similar land- 
atmosphere interaction study for Shanghai-one of the biggest, most densely populated urban cities in China. They drew a similar conclusion for the impacts of aerosol's direct effect on UHI in Shanghai. The authors proposed another mechanism for UCI, positing that buildings shadows reduce surface insolation. In addition, due to their geometry, buildings can change the wind vector, the eddy turbulence was enhanced by this process and the heat was transported from the ground surface to the higher air levels, which consequently reduce surface temperature. In the present work, UCI was examined via ground observations as well as WRF simulations.

This study aimed to analyze the physical process of the UHI/UCI effect as well as determine whether the WRF/Single-Layer Urban Canopy Model simulation can be successfully applied to the UHI. For the analysis of the physical process of the UHI effect, two cities Xi' an City in China, and Oklahoma City (OKC) in the United States were chosen, as this enabled assessment of the size and population impacts of urbanization. The marked areas on the country maps (Fig. 1) show the locations of Xi'an City $\left(34.0^{\circ}-34.6^{\circ} \mathrm{N}, 108.6^{\circ}-109.2^{\circ} \mathrm{E}\right)$ and $\mathrm{OKC}\left(35.2^{\circ}-35.8^{\circ} \mathrm{N}, 97.2^{\circ}-97.8^{\circ} \mathrm{W}\right)$. Both are inland cities and positioned at almost the same latitude. Thus, the UHI effect of each city should be related to the geometric properties, with little or no effects from the ocean. However, Xi'an City has an urban area of 319 sq. mi with a population density of about 
20,000/sq. mi, while the urban area for OKC is 410.6 sq. mi with a population density of about 2000/sq. mi. Thus, Xi'an City has a smaller urban area but a much larger population density.
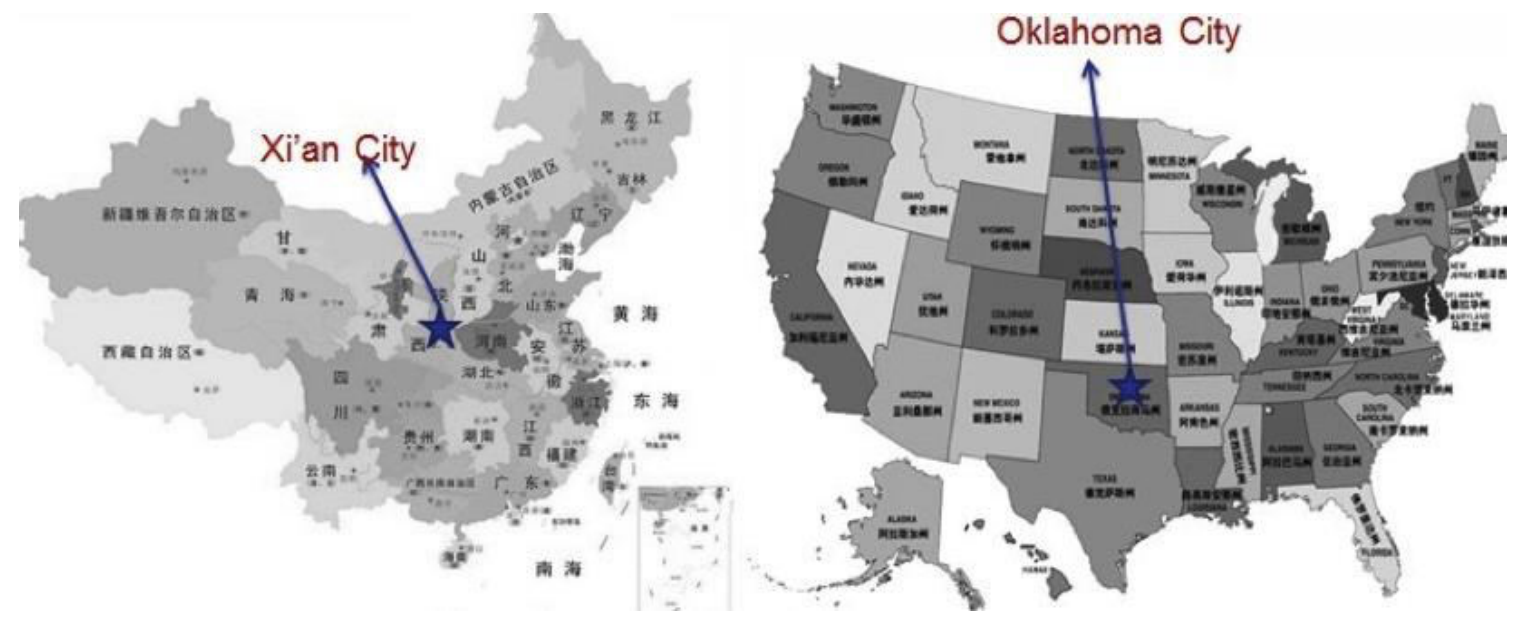

Figure 1: Locations of Xi'an City(http://a4.att.hudong.com/56/71/14300000932664128157715689635.jpg) and OKC(http://gdscseusa.net/upload/userfile/2010/03/12676954572021908495.gif) on their country maps.

The 2-m surface air temperature data and MODIS surface skin temperature data were used to analyze the UHI effects. The analyses revealed not only the presence of the UHI effect, but also its relation to the urban area size. In other words, cities characterized by large urban areas, like Xi'an city in China, would have a much more significant UHI effect. Moreover, the physical process of the UHI effect analyzed from $\mathrm{T}_{\text {air }}$ is clearly different from that of $\mathrm{T}_{\text {skin. }}$. However, the Single-Layer Urban Canopy Model for WRF Noah-LSM has its limitations with respect to capturing the influences of urban properties. 
The built-in USGS 24-category land-use data in WRF are outdated in many regions and cannot accurately represent the coverage of urban areas. In addition, the default building height for real urban cities cannot be adequately simulated, and some physical processes may still need to be added in the simulation to improve its accuracy.

\section{Joint Urban 2003}

The Joint Urban 2003 (JU2003) field campaign, sponsored by the U.S. Department of Defense, Defense Threat Reduction Agency, and the U.S. Department of Homeland Security, was conducted in OKC, Oklahoma, from June 28 through July 31, 2003. Over 150 scientists and engineers as well as many foreign institutions participated in this project aiming to investigate the atmospheric dispersion in OKC (Allwine and Flaherty 2006). Air temperature sensors, radiosondes, radars, lidars, sodars, and sonic anemometers were deployed as a part of this initiative, and the physical processesincluding surface energy balance in the urban area, the flows within the tall-building areas and street canyons, the effects of traffic on turbulence, the development of urban boundary layer, and the dispersion of tracers - were studied. Owing to the extent of this project, large amounts of high-resolution data were collected, resulting in hundreds of journal articles, presentations, and reports on this field project. 


\section{Data and Methods}

\section{Satellite Observation}

MODIS land cover data and the MODIS surface skin temperature $\left(\mathrm{T}_{\text {skin }}\right)$ data were used in this study to identify the UHI effect in OKC and Xi' an City. The MODIS instrument from which the data was obtained is mounted on NASA's Aqua (EOS pm) and Terra (EOS am) satellites. The MODIS/Terra Land Cover Types Yearly L3 Global 0.05Deg CMG (MOD12C1) apparatus was used in this study to create land-cover maps for OKC and Xi' an City. This land cover classification method includes multiple classification schemes, such as International Geosphere-Biosphere Programme (IGBP) classification scheme. The IGBP contains three developed land classes, eleven natural vegetation classes, and two additional classification schemes at $0.05^{\circ}$ resolution, the vegetation classes are emphasized, while the vegetation mosaic, snow information, and wetlands are excluded. After creating land-cover maps for $\mathrm{OKC}$ and $\mathrm{Xi}$ 'an City, the land cover types of urban regions and surrounding rural regions for both cities were compared. The MODIS11C3 Monthly CMG LST, which is the monthly daytime 3-min CMG Landsurface temperature data, was used in this research. The values of the land-surface temperature are those observed to the $0.05^{\circ}$ latitude/longitude grids (CMG). The study 
covered the period from 2001 to 2008 and both daytime and nighttime UHI effect in OKC and Xi'an City were studied.

\section{Ground Observation}

The Pacific Northwest National Laboratory (PNNL) HOBO 2-m air temperature data and the Atmospheric Turbulence and Diffusion Division (ATDD) flux site data were used to study the synoptic situation of the UHI effect in OKC. Both data sets were sourced from the JU2003 field project in OKC.

The PNNL set up 33 temperature sensors in a cross-section through the Central Business District (CBD) of OKC (Fig. 2). More specifically, sensors 1 through 17 were placed on Main Street, in the direction from west to east, while sensors 18 through 33 were placed on Robinson Avenue, in the direction from south to north. Sensor 9 was thus located at the centermost point of the city. In addition, as each sensor was only one or two blocks away from the next one, high spatial resolution data could be measured. The 2-m air temperature data through the downtown $\mathrm{OKC}$ were collected from these $\mathrm{HOBO}$ stations (Allwine and Flaherty 2006). In this research, the 2-m air temperature from ground observations was compared to the surface skin temperature from satellite observations, whereby the existence and the intensity of UHI event in OKC were confirmed. 


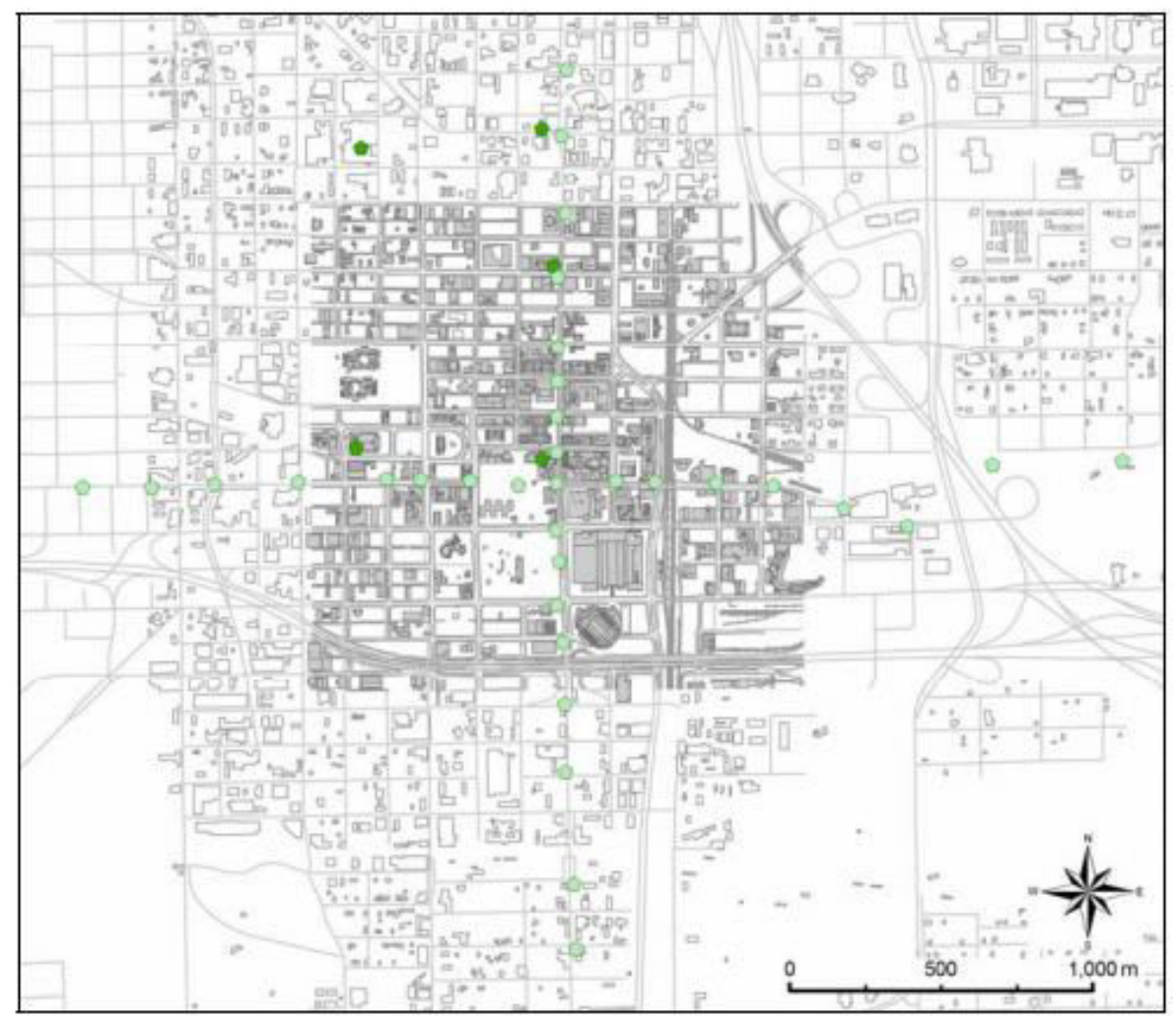

Figure 2: Overview of the PNNL Meteorological Station and HOBO locations. The light green pentagons are HOBOs, while the dark green pentagons are meteorological stations. Allwine and Flaherty 2006, (C) Courtesy of Battelle memorial Institute, operating contractor. From the Pacific Northwest National Laboratory for the U.S. Department of Energy.

The Atmospheric Turbulence and Diffusion Division (ATDD) deployed three surface flux sites, labeled as A, B and C in Figure 3, which shows their locations. Site A was located in a gravel and dirt parking lot in the west of the CBD of OKC, site B was located northeast of CBD in a grassy area, while site $\mathrm{C}$ was located on the top of a multiple-level concrete parking garage at the southwest corner of CBD (Hanna et al. 2011). Energy flux variables, such as net radiation, incoming shortwave radiation, sensible heat flux, and 
latent heat flux, were thus collected. In this research, the data obtained from site A and site B were excluded due to the unrealistically large value for the ground heat flux data observed from site A during nighttime and the large latent heat flux value observed from site B (Hanna et al. 2011). Consequently, the analyses performed in this study were based on the site $\mathrm{C}$ data set, because all the flux measurements had reasonable values. Although the data set contained several variables, the present study mainly focused on net radiation, incoming shortwave radiation, wind speed, and wind direction.

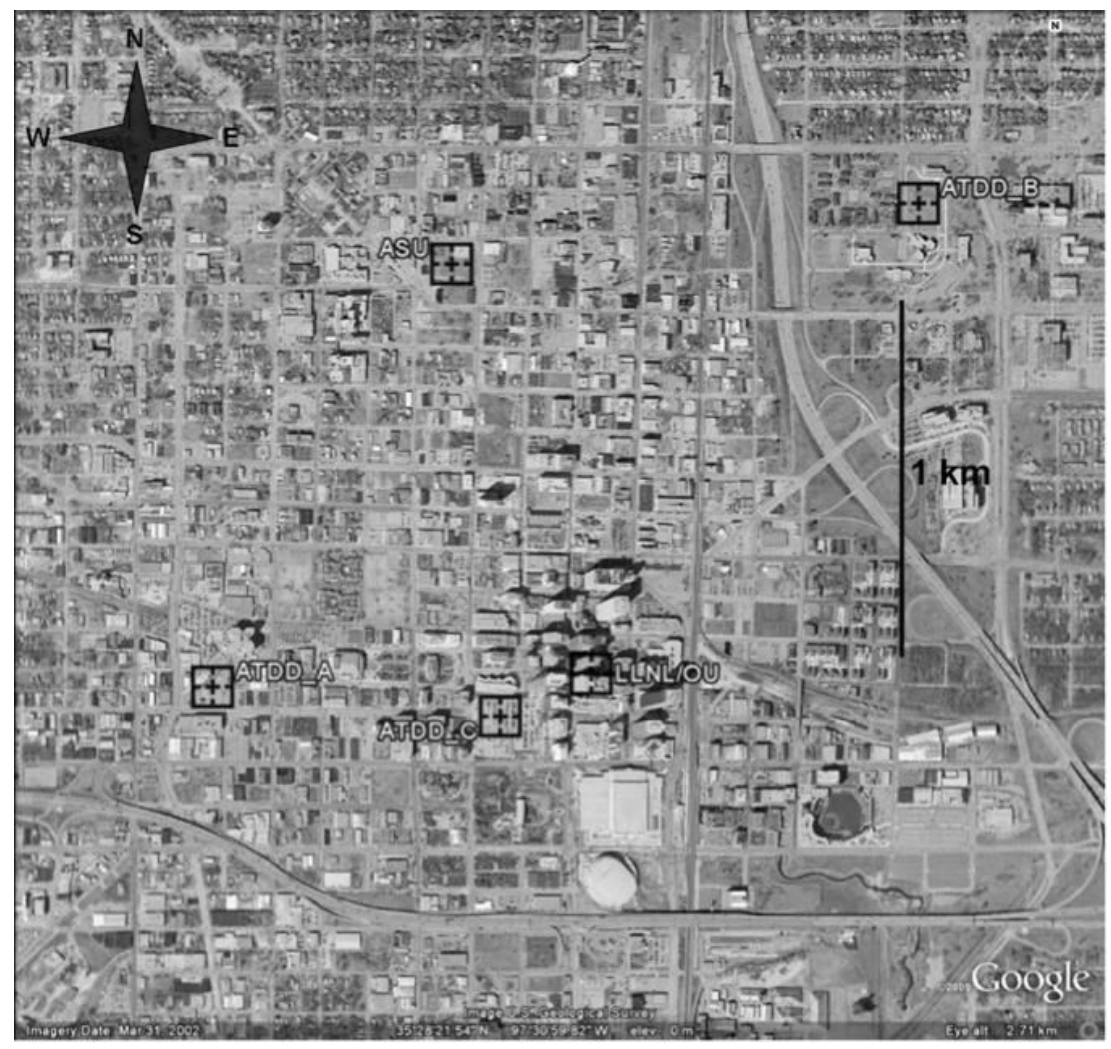

Figure 3: Overview of the Atmospheric Turbulence and Diffusion Division (ATDD) flux site locations. Hanna et al. 2011, CAmerican Meteorological Society 


\section{WRF/Single-Layer Urban Canopy Model (SLUCM) Simulation}

The Urban Canopy Model (UCM) is a single layer model (Fig. 4) coupled to the WRF model, and includes a 2-D street canyon. Figure 5 shows the radiation yielded by the single-layer urban canopy model (SLUCM), whereby SLUCM represents the physical process in the urban environment and provides better forecasts for urban areas. It has a simplified urban geometry, and includes some of the effects of modified wind profile in the canopy layer, as well as reflection of shortwave radiation and long-wave radiation, shadowing from tall buildings, and heat transfer in roads, walls and roofs (Kusaka et al. 2001).

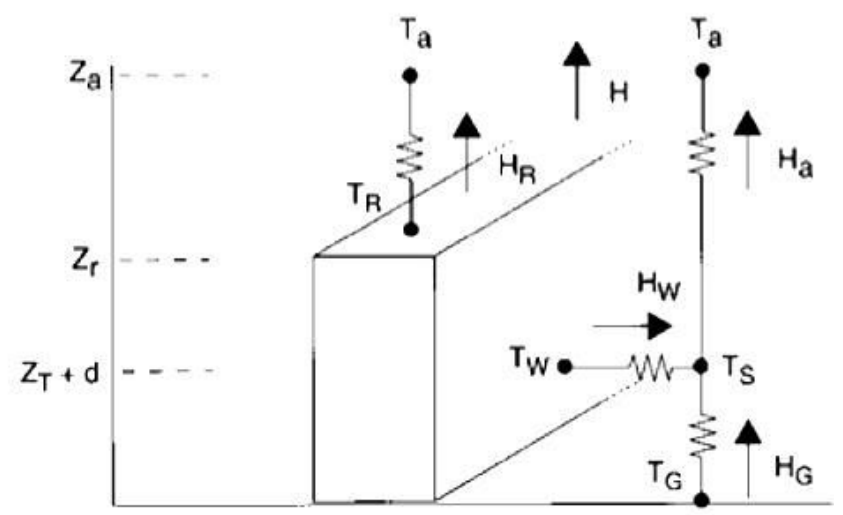

Figure 4: Single-Layer Urban Canopy Model. Ta: air temperature at reference height $Z a$. $T_{R}$ : building roof temperature. $\mathrm{T}_{\mathrm{W}}$ : building wall temperature. $\mathrm{T}_{\mathrm{G}}$ : road temperature. $\mathrm{T}_{\mathrm{S}}$ : temp defined at $\mathrm{Z}_{\mathrm{T}}+\mathrm{d}$. $\mathrm{H}$ : sensible heat exchange at reference height. Ha: sensible heat flux from the canyon space to atmosphere. $\mathrm{H}_{\mathrm{W}}$ : sensible heat flux from wall to canyon space. $\mathrm{H}_{\mathrm{G}}$ : sensible heat flux from road to canyon space. $\mathrm{H}_{\mathrm{R}}$ : sensible heat flux from roof to the atmosphere. Kusaka et al. 2001, CSpringer 


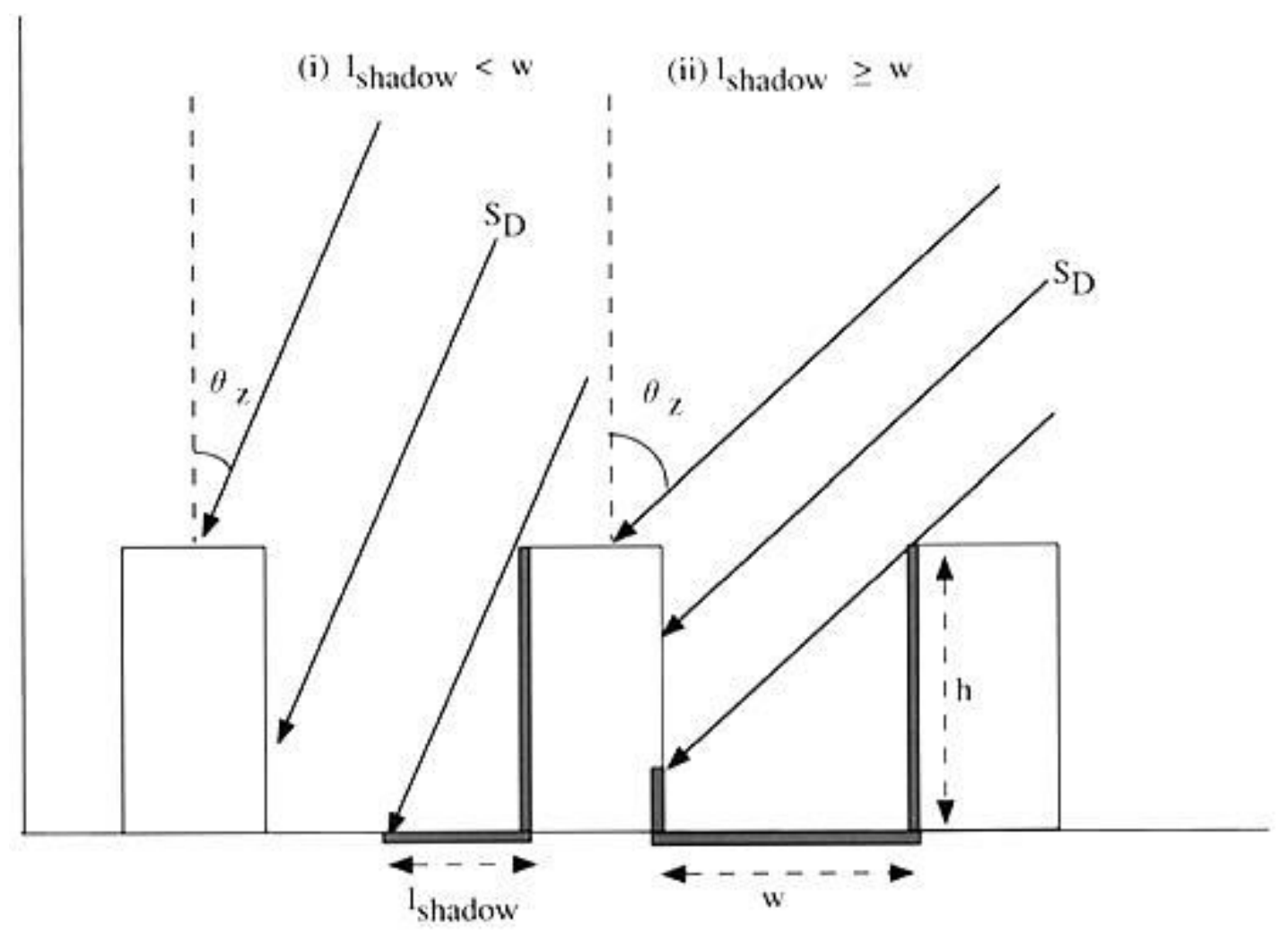

Figure 5: Radiation of the single-layer urban canopy model. $\mathrm{S}_{\mathrm{D}}$ : direct solar radiation on a horizontal surface. $w$ : normalized road width. h: normalized building height. $w+r=1$, where $r$ is the normalized roof width. $1_{\text {shadow }}$ : normalized shadow length on the road. $\theta z$ : solar zenith angle. Kusaka et al. 2001, OSpringer

The atmospheric input in Table I represents the current state of the atmosphere, and it is used in modeling as a forcing parameter. On the other hand, the atmospheric output from the single-layer urban canopy model in Table II is used to update the atmospheric models. Table III shows the surface parameters and canyon dimensions used in the models, while Table IV provides some physical constants used in the models (Kusaka et al. 2001). 
TABLE 1: Atmospheric input to the single-layer urban canopy model

\begin{tabular}{lll}
\hline Input data & Symbol & Unit \\
\hline Reference height & $z_{a}$ & {$[\mathrm{~m}]$} \\
Temperature at $z_{a}$ & $T_{a}$ & {$[\mathrm{~K}]$} \\
Zonal wind at $z_{a}$ & $u_{a}$ & {$\left[\mathrm{~m} \mathrm{~s}^{-1}\right]$} \\
Meridional wind at $z_{a}$ & $v_{a}$ & {$\left[\mathrm{~m} \mathrm{~s}^{-1}\right]$} \\
Specific humidity at $z_{a}$ & $q_{a}$ & {$\left[\mathrm{~kg} \mathrm{~kg}^{-1}\right]$} \\
Downward direct solar radiation on a horizontal surface & $S_{D}$ & {$\left[\mathrm{~W} \mathrm{~m}^{-2}\right]$} \\
Downward diffuse solar radiation on a horizontal surface & $S_{Q}$ & {$\left[\mathrm{~W} \mathrm{~m}{ }^{-2}\right]$} \\
Downward longwave radiation on a horizontal surface & $L^{\downarrow}$ & {$[\mathrm{rad}]$} \\
Latitude & $\phi$ & {$[\mathrm{rad}]$} \\
Solar declination & $\delta$ & {$[\mathrm{rad}]$} \\
\hline
\end{tabular}

TABLE 2: Atmospheric output from the single-layer urban canopy model

\begin{tabular}{lll}
\hline Output variable & Symbol & Unit \\
\hline Sensible heat flux & $H$ & {$\left[\mathrm{~W} \mathrm{~m}^{-2}\right]$} \\
Latent heat flux & $1 E$ & {$\left[\mathrm{~W} \mathrm{~m}^{-2}\right]$} \\
Groundheat flux & $G$ & {$\left[\mathrm{~W} \mathrm{~m}^{-2}\right]$} \\
Reflected shortwave radiation & $S^{\uparrow}$ & {$\left[\mathrm{W} \mathrm{m}^{-2}\right]$} \\
Emitted longwave radiation & $L^{\uparrow}$ & {$\left[\mathrm{W} \mathrm{m}^{-2}\right]$} \\
Momentum flux & $\tau$ & {$\left[\mathrm{kg} \mathrm{m}^{-1} \mathrm{~s}^{-2}\right]$} \\
Zonal momentum flux & $\tau_{x}$ & {$\left[\mathrm{~kg} \mathrm{~m}^{-1} \mathrm{~s}^{-2}\right]$} \\
Meridional momentum flux & $\tau_{y}$ & {$\left[\mathrm{~kg} \mathrm{~m}^{-1} \mathrm{~s}^{-2}\right]$} \\
Roof surface temperature & $T_{R}$ & {$[\mathrm{~K}]$} \\
Wall surface temperature & $T_{W}$ & {$[\mathrm{~K}]$} \\
Road surface temperature & $T_{G}$ & {$[\mathrm{~K}]$} \\
\hline
\end{tabular}


TABLE 3: Surface parameters and canyon dimensions

\begin{tabular}{llll}
\hline Parameter & Symbol & Value & Unit \\
\hline Roof level (building height) & $z_{r}$ & 15 & [m] \\
Normalized building height & $h$ & 0.5 & \\
Normalized roof width & $r$ & 0.25 & \\
Normalized road width & $w$ & 0.75 & \\
Urban area ratio for a grid & $A_{u}$ & 1 & \\
Vegetation area ratio for a grid & $A_{v}$ & 0 & \\
Roughness length for momentum above city & $z_{0 m}$ & 0.5 & {$[\mathrm{~m}]$} \\
Roughness length for momentum above canyon & $z_{0}$ & 0.667 & {$[\mathrm{~m}]$} \\
Roughness length above roof & $z_{0 R}$ & 0.005 & {$[\mathrm{~m}]$} \\
Zero plane displacement height & $d$ & 2.3 & [m] \\
Roof surface albedo & $\alpha_{R}$ & 0.2 & \\
Wall surface albedo & $a_{W}$ & 0.2 & \\
Road surface albedo & $\alpha_{G}$ & 0.2 & \\
Roof surface emissivity & $\epsilon_{R}$ & 0.97 & \\
Wall surface emissivity & $\epsilon_{W}$ & 0.97 & \\
Road surface emissivity & $\epsilon_{G}$ & 0.97 & \\
Canyon orientation & $\theta_{\text {can }}$ & $n \pi / 8$ & [rad] \\
& & $(n=0-7)$ & \\
\hline
\end{tabular}

TABLE 4: Physical constants used in the models

\begin{tabular}{llll}
\hline Physical constant & Symbol & Value & Unit \\
\hline Von Karman constant & $k$ & 0.4 & \\
Stefan-Boltzmann constant & $\sigma$ & $5.67 \times 10^{-8}$ & {$\left[\mathrm{~W} \mathrm{~m}^{-2} \mathrm{~K}^{-4}\right]$} \\
Heat capacity of dry air & $c_{p}$ & 1004.64 & {$\left[\mathrm{~J} \mathrm{~kg}^{-1} \mathrm{~K}^{-1}\right]$} \\
Volumetric heat capacity of roof & $\rho_{R C R}$ & $2.01 \times 10^{6}$ & {$\left[\mathrm{~J} \mathrm{~m}^{-3} \mathrm{~K}^{-1}\right]$} \\
Volumetric heat capacity of wall & $\rho_{W C W}$ & $2.01 \times 10^{6}$ & {$\left[\mathrm{~J} \mathrm{~m}^{-3} \mathrm{~K}^{-1}\right]$} \\
Volumetric heat capacity of road & $\rho_{G C G}$ & $2.01 \times 10^{6}$ & {$\left[\mathrm{~J} \mathrm{~m}^{-3} \mathrm{~K}^{-1}\right]$} \\
Thermal conductivity of roof & $\lambda_{R}$ & 2.28 & {$\left[\mathrm{~W} \mathrm{~m}^{-1} \mathrm{~K}^{-1}\right]$} \\
Thermal conductivity of wall & $\lambda_{W}$ & 2.28 & {$\left[\mathrm{~W} \mathrm{~m}^{-1} \mathrm{~K}^{-1}\right]$} \\
Thermal conductivity of road & $\lambda_{G}$ & 2.28 & {$\left[\mathrm{~W} \mathrm{~m}^{-1} \mathrm{~K}^{-1}\right]$} \\
\hline
\end{tabular}


In this research, 24-h simulations began at 1200 UTC (0600 LST) on July 19, 2003, and were conducted with the NCEP North American Regional Reanalysis (NARR) data. This simulation was performed by the Single-Layer Urban Canopy Model (SLUCM). The horizontal domain created for this simulation was comprised of three nested domains with a grid spacing of $25 \mathrm{~km}, 5 \mathrm{~km}$, and $1 \mathrm{~km}$ (Fig. 6).

Two simulations were performed: a control run without SLUCM and a sensitive run with SLUCM. The simulated $\mathrm{T}_{\text {skin }}$ measured in urban regions in $\mathrm{OKC}$ for the case of sensitive run and control run were compared. In addition, for the case of sensitive run, the simulated surface skin temperatures of the urban region and rural region in $\mathrm{OKC}$ were compared. The SLUCM-simulated variables were compared to the surface temperature wind speed and direction. 


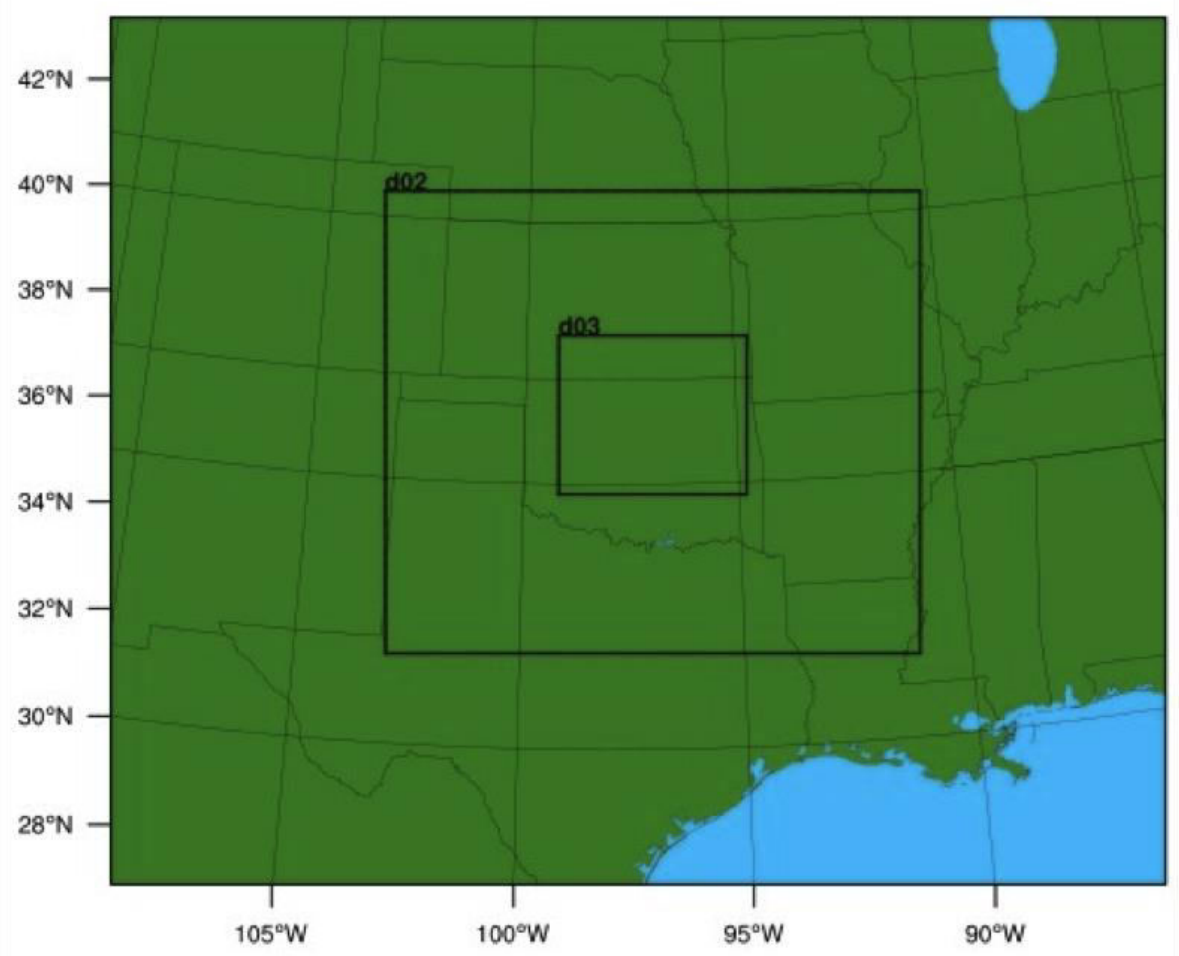

Figure 6: Three nesting domains with 25,5 , and $1 \mathrm{~km}$ grid spacing in WRF simulation.

\section{Results}

\section{Satellite Observation Analysis}

Xi' an City and OKC are both inland cities, located at $35^{\circ} \mathrm{N}$, with similar cloud cover during July. Thus, they are expected to receive a similar amount of solar radiation. Based on the MODIS land cover data, the red mapped area in Fig. 7a and Fig. 7c correspond to the urban land cover for OKC and Xi'an City, respectively (land cover $=13$, urban). These maps suggest that the surrounding land cover types of these two cities are 
not the same. Namely, there are more croplands (land cover $=12$, cropland) and mixed forest (land cover $=5$, mixed forest) surround Xi'an City, while OKC is mostly surrounded by grassland (land cover $=10$, grassland) and croplands (land cover $=12$, cropland).

MODIS monthly land surface skin temperatures recorded by Terra at 10:30 in the morning (local time) clearly show that $\mathrm{T}_{\text {skin }}$ varies with land cover types for both $\mathrm{OKC}$ and Xi'an City (Fig.7b and Fig.7d). Evidently, $\mathrm{T}_{\text {skin }}$ over the urban area is much higher than the $\mathrm{T}_{\text {skin }}$ measured in the surrounding rural area for both cities. In OKC, the value of $\mathrm{T}_{\text {skin }}$ observed over the urban area is about $299 \mathrm{~K}$, while the $\mathrm{T}_{\text {skin }}$ for its rural area is around 295 K-298 K. Similarly, in Xi'an City, the value of $\mathrm{T}_{\text {skin }}$ for urban and rural area is $308 \mathrm{~K}$ and is $306 \mathrm{~K}$, respectively. 
TABLE 5: MODIS land cover types

\begin{tabular}{|l|l|l|l|}
\hline 1 & $\begin{array}{l}\text { Evergreen needle leaf } \\
\text { forest }\end{array}$ & 9 & Savannas \\
\hline 2 & Evergreen broadleaf forest & 10 & Grassland \\
\hline 3 & $\begin{array}{l}\text { Deciduous needle leaf } \\
\text { forest }\end{array}$ & 11 & Permanent wetland \\
\hline 4 & Deciduous broadleaf forest & 12 & Croplands \\
\hline 5 & Mixed forest & 13 & Urban and built-up \\
\hline 6 & Closed shrub land & 14 & $\begin{array}{l}\text { Cropland/natural } \\
\text { vegetation mosaic }\end{array}$ \\
\hline 7 & Open shrub land & 15 & Snow and ice \\
\hline 8 & Woody savannas & 16 & $\begin{array}{l}\text { Barren or sparsely } \\
\text { vegetated }\end{array}$ \\
\hline
\end{tabular}



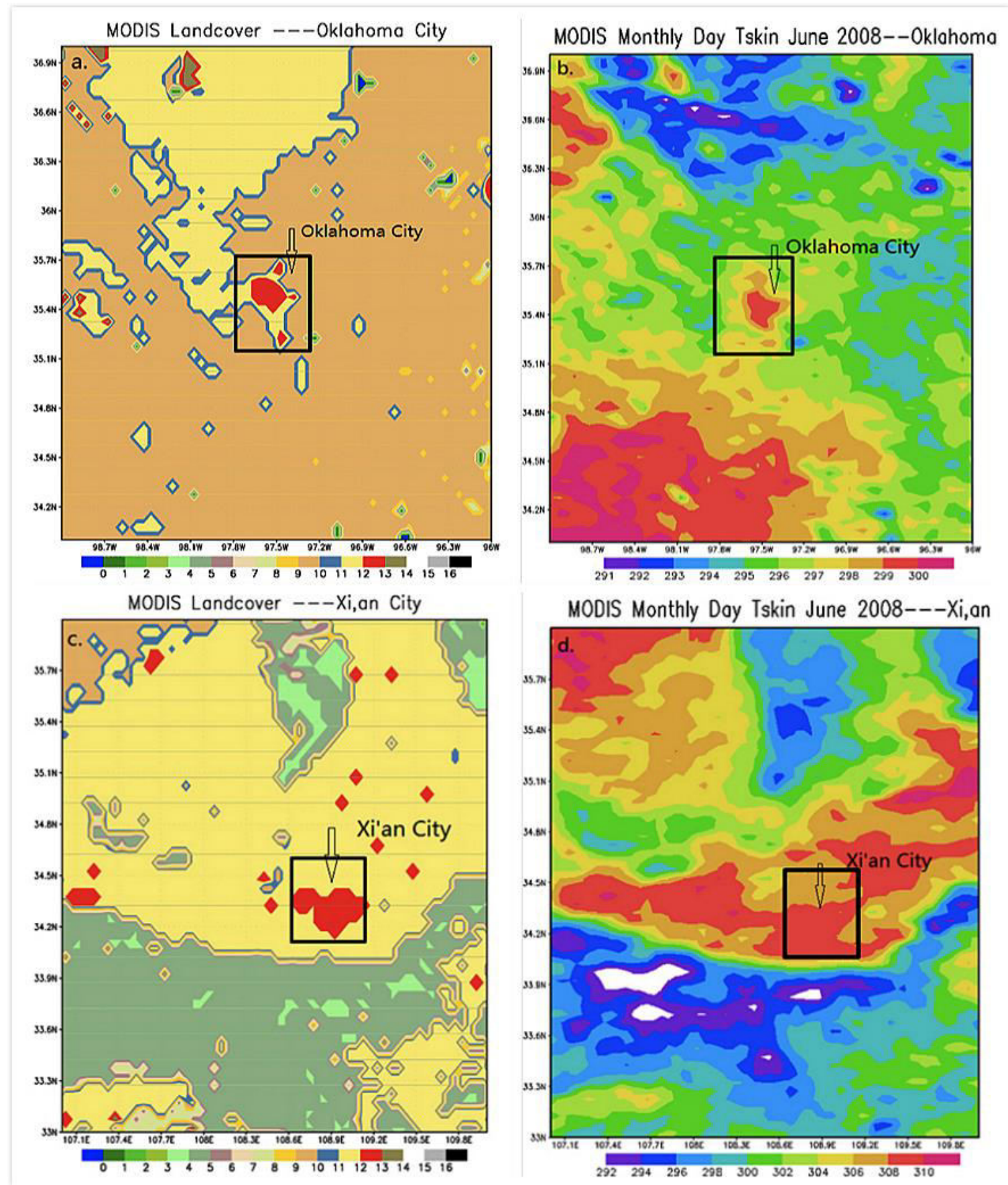

Figure 7: MODIS land surface cover type of (a) Oklahoma and (c) Xi'an. Land surface cover type is given in Table 5. Land cover $=13$ denotes urban area (red mapped areas). Locations of OKC and Xi'an City are marked in the figures. MODIS monthly daytime land surface temperature (expressed in $\mathrm{K}$ ) was recorded in June 2008 by Terra at 10:30 local time for (b) OKC in June 2008 and (d) Xi'an City. 
The temperature difference is calculated based on the following expression:

$$
\mathrm{T}_{\text {diff }}=\mathrm{T}_{\text {urban }}-\mathrm{T}_{\text {nonurban }}
$$

where $T_{\text {urban }}$ and $T_{\text {nonurban }}$ indicate the surface skin temperature averaged over all pixels observed over the urban and rural regions, respectively, within the area shown in Figure 7. As can be seen, both OKC and Xi' an City have a significant UHI effect. For OKC, the monthly averaged $\mathrm{T}_{\text {skin }}$ observed over urban areas are always higher than those over rural areas (Fig. 8). The value for daytime $\mathrm{T}_{\text {diff }}$ in $\mathrm{OKC}$ is in the $0.5-4.4{ }^{\circ} \mathrm{C}$ range (Fig. 8b), while for the nighttime, the $\mathrm{T}_{\text {diff }}$ ranges from 0.6 to $3.0{ }^{\circ} \mathrm{C}$ (Fig. 8d). In comparison, for Xi'an City, the monthly averaged $\mathrm{T}_{\text {skin }}$ observed over urban areas are also higher than the $\mathrm{T}_{\text {skin }}$ over its surrounding rural areas during most of the year. The only exception is a short period in January (Fig. 9a), when the daytime $\mathrm{T}_{\text {diff }}$ value ranged from -0.4 to $7.2{ }^{\circ} \mathrm{C}$ (Fig. 9b), and the nighttime $\mathrm{T}_{\text {diff }}$ ranged from 2.5 to $4.2{ }^{\circ} \mathrm{C}$ (Fig. 9d). Usually, UHI is stronger in warmer seasons relative to colder periods. In addition, for $\mathrm{OKC}$, the strongest daytime UHI occurred around May and the weakest UHI around December (Fig. 8b). On the other hand, the strongest nighttime UHI was measured in July and the weakest UHI occurred around February (Fig. 8d). For Xi'an City, the strongest daytime UHI was measured around May and the weakest around January (Fig. 9b). In addition, the strongest nighttime UHI was also recorded for the period around May, while the weakest nighttime UHI occurred in November (Fig. 9d). 

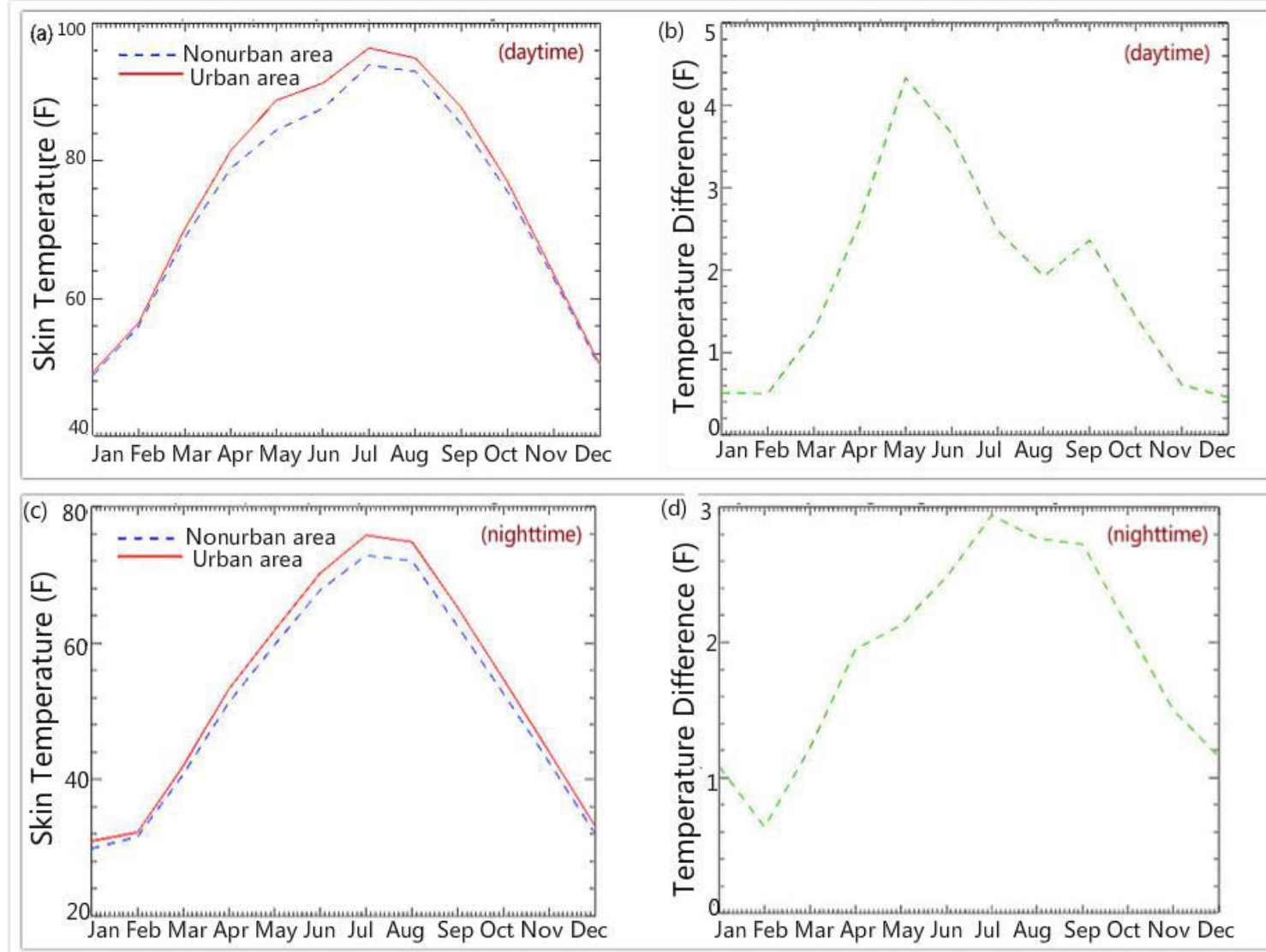

Figure 8: (a) OKC monthly averaged daytime skin temperature (2001-2008), (b) OKC monthly averaged daytime skin temperature difference (urban - nonurban), (c) OKC monthly averaged nighttime skin temperature (2001-2008), (d) OKC monthly averaged nighttime skin temperature difference (urban nonurban). 

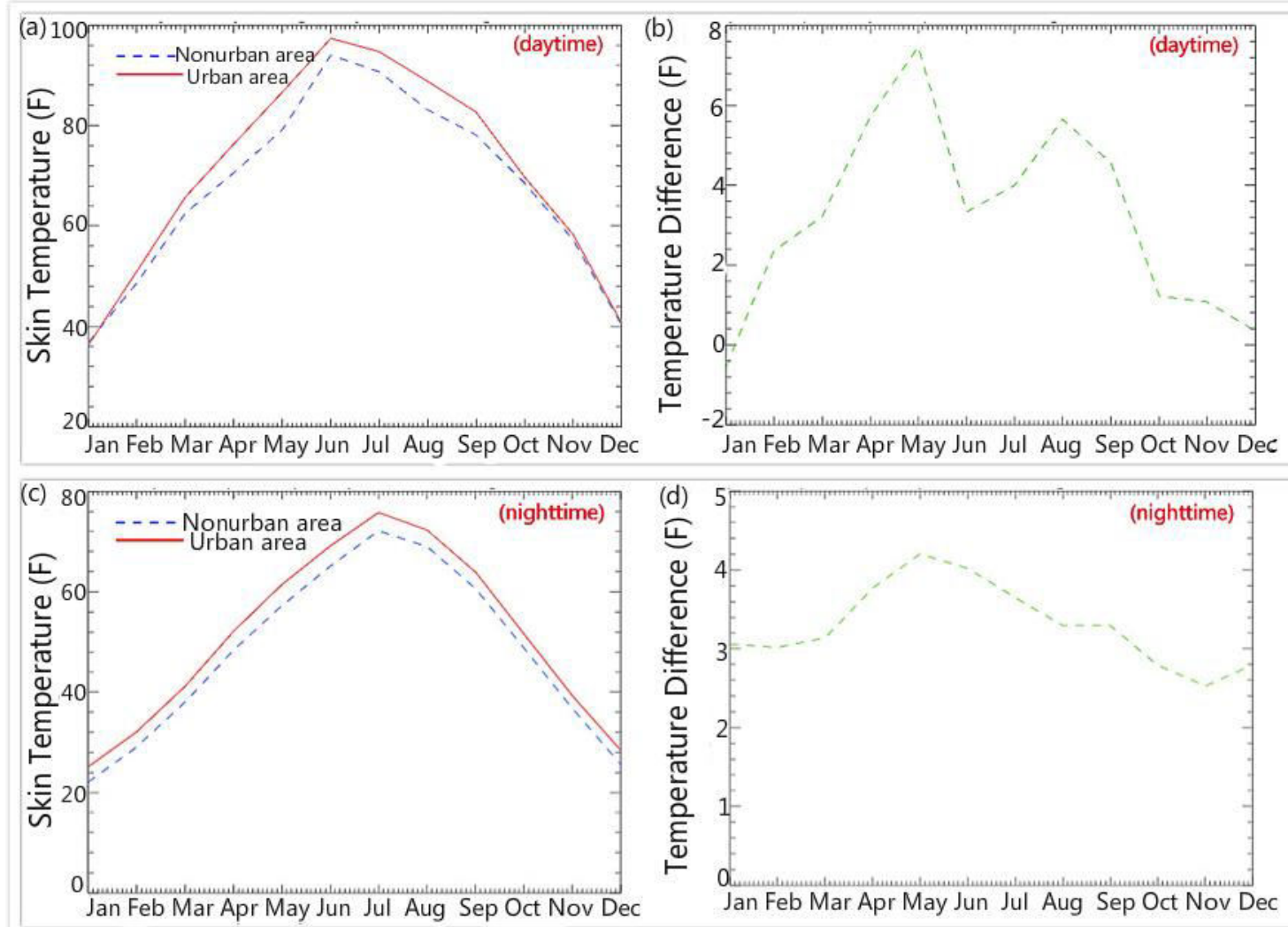

Figure 9: (a) Xi'an City monthly averaged daytime skin temperature (2001-2008), (b) Xi'an City monthly averaged daytime skin temperature difference (urban - nonurban), (c) Xi'an City monthly averaged nighttime skin temperature (2001-2008), (d) Xi'an City monthly averaged nighttime skin temperature difference (urban - nonurban).

A comparison of the UHI effects of OKC and Xi'an City (Fig. 10a and Fig. 10b) reveals that the $\mathrm{T}_{\text {diff }}$ for both daytime and nighttime in Xi' an City are always higher than those in $\mathrm{OKC}$, especially during daytime at the beginning of May and August. The value of $\mathrm{T}_{\text {diff }}$ at the beginning of May for Xi' an City is about $7.8^{\circ} \mathrm{C}$, while for $\mathrm{OKC}$ it is about $3.9^{\circ} \mathrm{C}$. Moreover, $\mathrm{T}_{\text {diff }}$ for $\mathrm{Xi}$ ' an City measured at the beginning of August is about $6.0^{\circ} \mathrm{C}$, while it is $2.0^{\circ} \mathrm{C}$ for $\mathrm{OKC}$ (Fig. 10a). It can also be noted that the nighttime differences are smaller than those found for the daytime temperatures (Fig. 10b), which 
suggests that the UHI effect in Xi'an City is stronger and much more significant than that in OKC. This may due to higher and more densely distributed buildings, and a larger population density in Xi'an City. Simply put, UHI is determined by the city characteristics (size, building density, population, etc.) and exhibits clear seasonality and diurnal features.
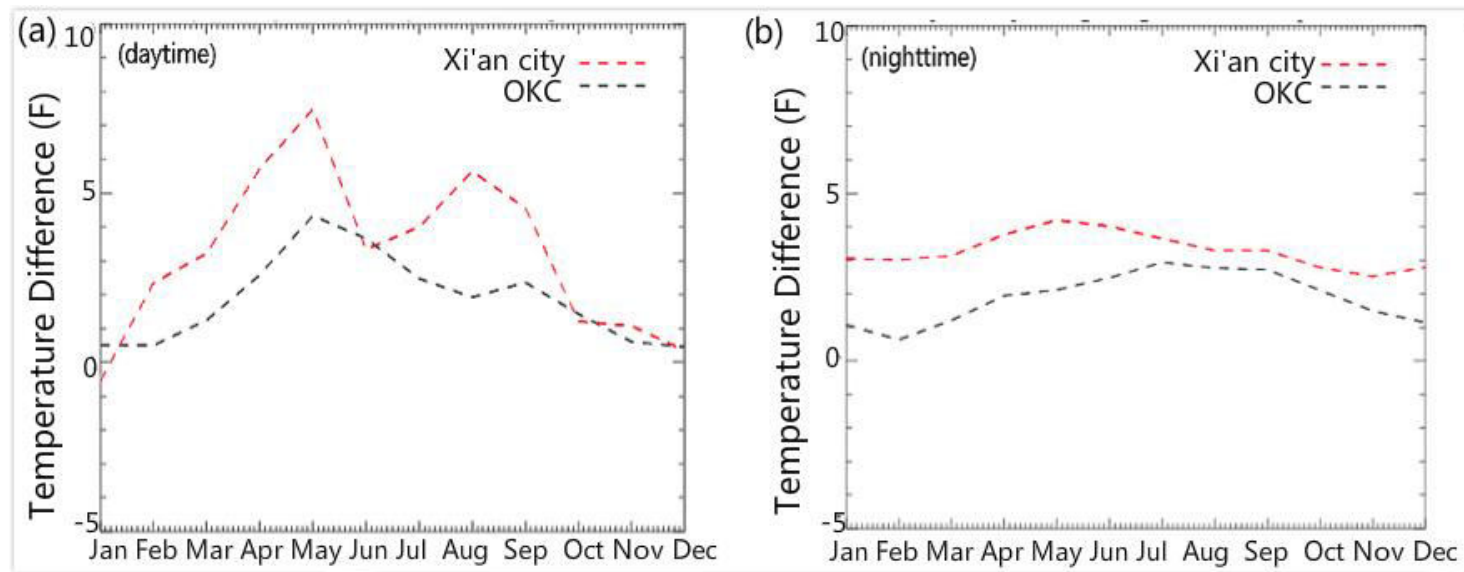

Figure 10: (a) Xi'an City and OKC monthly averaged daytime skin temperature difference (urban nonurban), (b) Xi'an City and OKC monthly averaged nighttime skin temperature difference (urban -nonurban)

In conclusion, satellite observations of $\mathrm{T}_{\text {skin }}$ provide a good index for assessing the UHI effects. Based on the satellite obtained $\mathrm{T}_{\text {skin }}$ field, the UHI is evident for OKC and Xi'an City, both of which are inland cities. In addition, given its global coverage and high spatial resolution, satellite retrieval can be applied to a medium-sized city in North America as well as a big city in China. 


\section{Ground Observation Analysis}

The calculated 2-m $\mathrm{T}_{\text {air }}$ difference $(\Delta \mathrm{T})$ for $00 \mathrm{UTC}, 06 \mathrm{UTC}, 12 \mathrm{UTC}$ and $18 \mathrm{UTC}$ in the X-distance on July 19, 2003 showed a unique UCI at the center of the downtown (station 9; Fig. 11a). The values of $\Delta \mathrm{T}$ at the $\mathrm{y}$-axis were calculated based on the equation:

$$
\Delta \mathrm{T}=\mathrm{T}_{\mathrm{i}}-\mathrm{T}_{\text {mean }}(\mathrm{I}=1, \ldots, 17)
$$

where $T_{i}$ is the 2-meter $T_{\text {air }}$ collected from station No. $\mathrm{i}(\mathrm{i}=1, \ldots, 17)$ and $\mathrm{T}_{\text {mean }}$ is the averaged 2-meter $\mathrm{T}_{\text {air }}$ from all 33 stations. The temperature difference measured for the station No. 9 was much lower than that observed at the other stations, especially at noon (Fig. 11a). This discrepancy may have been due to the fact that station No. 9 was located at the centermost point in $\mathrm{OKC}$ town center and is surrounded by tall buildings.

The greatest range of $\mathrm{T}_{\text {skin }}$ among different stations occurred at $18 \mathrm{UTC}$, and the amount of incoming solar radiation is the highest at noon (18 UTC). In contrast, at around $06 \mathrm{UTC}$, as there is no incoming solar radiation, the variation in the temperature difference is reduced. Furthermore, at 18 UTC, the two highest values $-0.8{ }^{\circ} \mathrm{C}$ and $1.0{ }^{\circ} \mathrm{C}$ —were obtained at stations No. 22 and No. 28 (Fig. 11b), respectively. In addition, the lowest value of $-0.7{ }^{\circ} \mathrm{C}$ was recorded at station No. 25 . 
The diurnal cycles of $\mathrm{T}_{\text {air }}$ for station No. 22 , station No. 25 , and station No. 28 were similar and were characterized by peak values at 21 UTC and minimum values at 12 UTC (Fig. 12). However, the $\mathrm{T}_{\text {air }}$ from station No. 25 (red curve) was always below those $\mathrm{T}_{\text {air }}$ observed at the other two stations. This may be due to the fact that only station No. 25 is located in the vicinity of the centermost point in the OKC town center (see Fig. 13). Tall buildings in the downtown center exhibit several important effects that contribute to this finding. More specifically, they block sunshine and cast shadows on station No. 25. In addition, the walls of tall buildings lift air parcels (a dynamic mechanism similar to mountain lift) and increase local circulation. This process enhances eddy turbulence and transports heat from the ground surface to the higher air levels. As a result of all these mechanisms, the air temperature at station No. 25 is reduced. It is critical to note that measurements obtained at station No. 9 and station No. 25 indicate that OKC may have exhibited a UCI effect on its urban regions. This new feature, which was not observed from the $T_{\text {skin }}$ field, illustrates the difference between $T_{\text {air }}$ and $\mathrm{T}_{\text {skin }}$ in terms of physical effects and magnitudes (Jin and Dickinson 2010). 

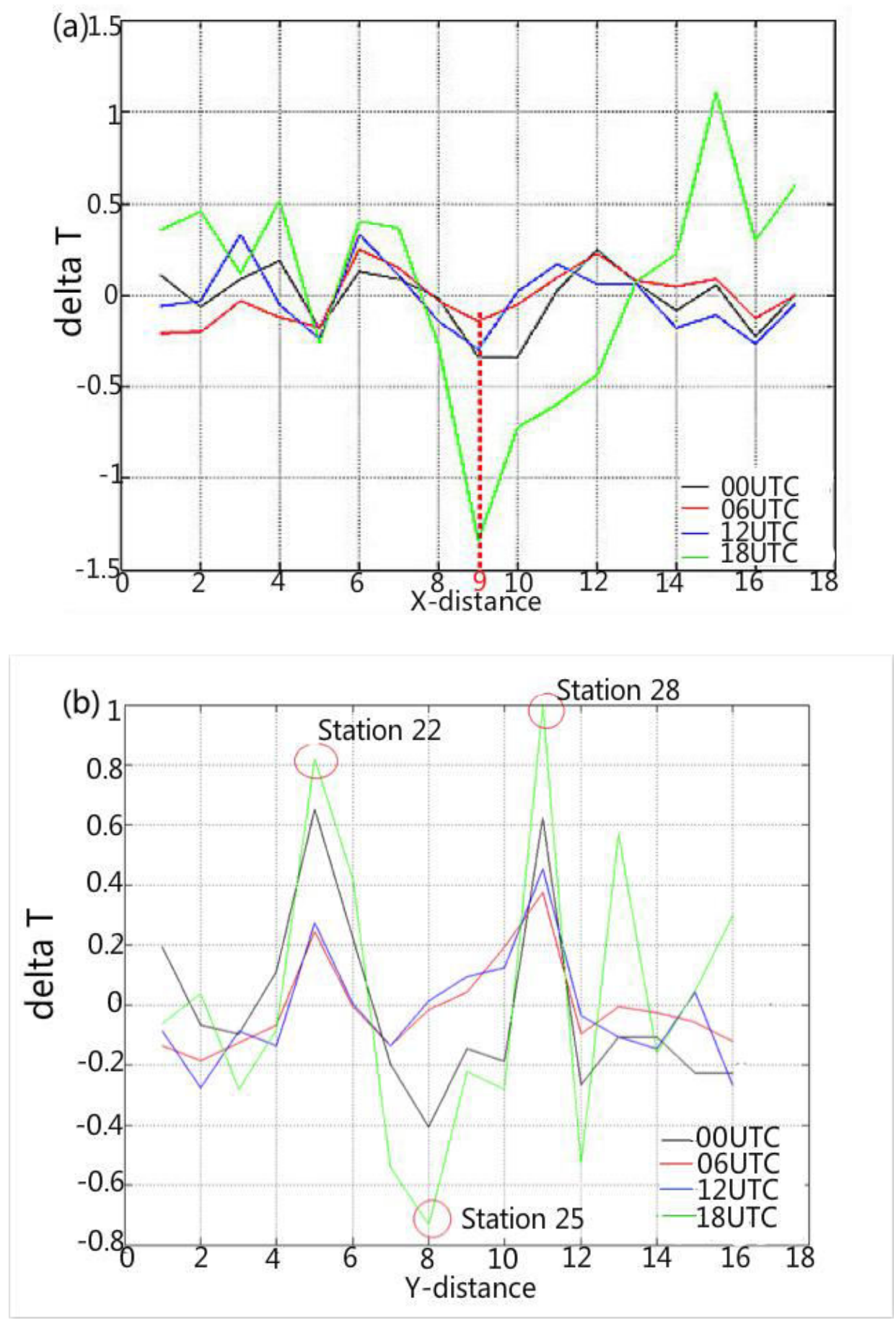

Figure 11: The Delta $\mathrm{T}$ values for 2-meter air temperatures for each station in (a) X-direction and (b) $\mathrm{Y}$ direction. 


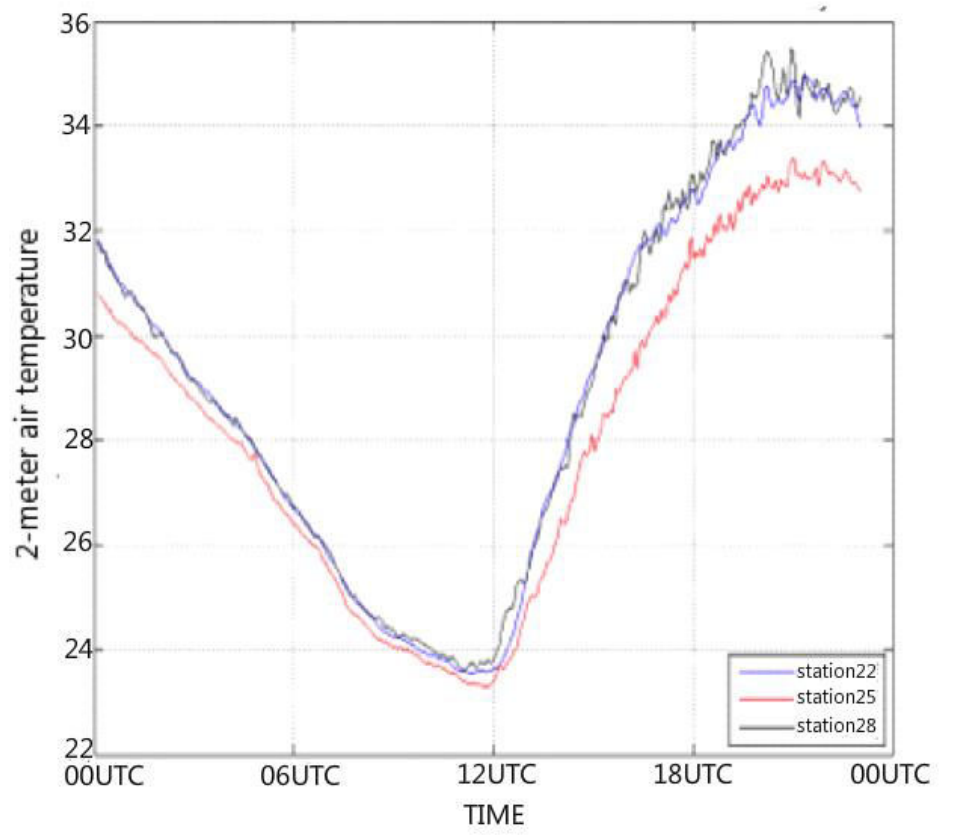

Figure 12: 24-h diurnal variation of 2-meter air temperatures from PNNL HOBO station No. 22, station No. 25, and station No. 28.

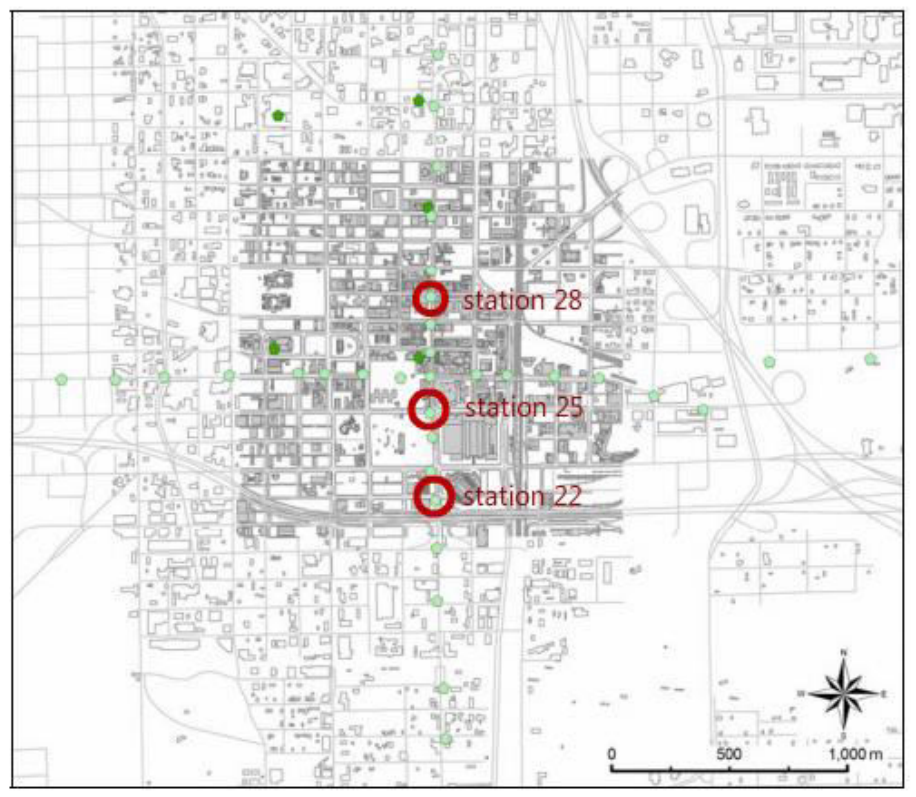

Figure 13: Map of locations of the PNNL HOBO station No. 22, station No. 25, and station No. 28. 
The soil temperatures at $32 \mathrm{~cm}$ and $64 \mathrm{~cm}$ in OKC collected from ATDD flux site C differ from $\mathrm{T}_{\text {air }}$. While there were fewer diurnal variations, overall, a better diurnal cycle was provided by the soil temperature at $32 \mathrm{~cm}$, as it ranged from $27{ }^{\circ} \mathrm{C}$ to $44{ }^{\circ} \mathrm{C}$. The peak value was obtained at 22 UTC, while the minimum obtained at 13 UTC. In addition, as the propagation from the surface to the lower soil layer will cause heat reduction and warmer time delay, the soil temperature at $64 \mathrm{~cm}$ has less pronounced diurnal variations. It is also characterized by a phase shift, where a peak value of $13{ }^{\circ} \mathrm{C}$ was obtained at 23 UTC, compared to the soil temperature at $32 \mathrm{~cm}$ with a peak value of $44{ }^{\circ} \mathrm{C}$ at $22 \mathrm{UTC}$ (Fig. 14).

Sensible heat flux is the process whereby the heat energy is transferred from Earth's surface to the atmosphere - a phenomenon mostly associated with the difference between $\mathrm{T}_{\text {skin }}$ and $\mathrm{T}_{\text {air }}$ In $\mathrm{OKC}$, sensible heat flux shows a clear diurnal cycle, with the peak value of about $170 \mathrm{~W} \mathrm{~m}^{-2}$ around 3:00 in the afternoon (local time), while the minimum value appears around 6:00 in the morning (Fig. 15). The fact that the peak value of sensible heat flux occurred at 3:00 pm instead of at noon may be due to the following reasons: the sensible heat flux is determined by the difference between $\mathrm{T}_{\text {skin }}$ and $\mathrm{T}_{\text {air }}$, while the solar radiation reaches its peak value at noon. As the heat accumulates at the surface, the $\mathrm{T}_{\text {skin }}$ increases, and reaches its peak value at 1:00 - 2:00 in the afternoon. In addition, the 
heated surface keeps warming up the air at 2-meter elevation from the ground, causing the $\mathrm{T}_{\text {air }}$ to increase. As a result, the difference between $\mathrm{T}_{\text {skin }}$ and $\mathrm{T}_{\text {air }}$ reached the peak value at 3:00 in the afternoon (local time).

Wind speed and wind direction are two important factors influencing the UHI effect. Usually, the wind speed is reduced through urban areas due to the surface roughness. However, if the wind speed increases due to the canyon lift or turbulence, it reduces the intensity of the UHI effect. The wind speed in OKC is around $3 \mathrm{~m} / \mathrm{s}$, and the urban regions in OKC mostly experience southerly winds (Fig. 16). Wind speed is higher during daytime (at $20 \mathrm{UTC}$ ), with a value of $3 \mathrm{~m} / \mathrm{s}$, and is reduced at night (around 11 UTC), to the value of $0.2 \mathrm{~m} / \mathrm{s}$. Furthermore, while wind direction varies during daytime, it has a typical value of $150^{\circ}$. However, it changes abruptly to $270^{\circ}$ at $15 \mathrm{UTC}$ and 09 UTC. This suggests that urban surface wind directions can be significantly changed due to various factors, such as regional circulation or surface temperature gradient. 


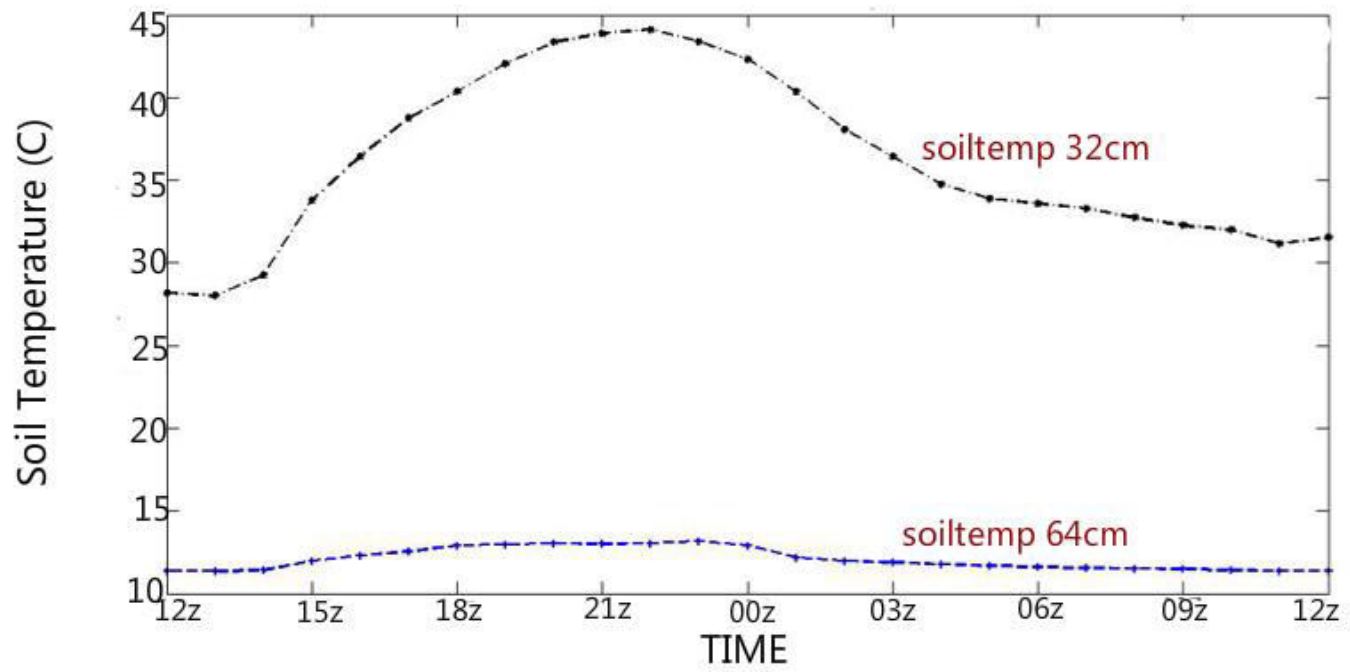

Figure 14: ATDD flux site $\mathrm{C}$ observed 24-h diurnal variation of soil temperature (C) at $32 \mathrm{~cm}$ and $64 \mathrm{~cm}$ in $\mathrm{OKC}$.

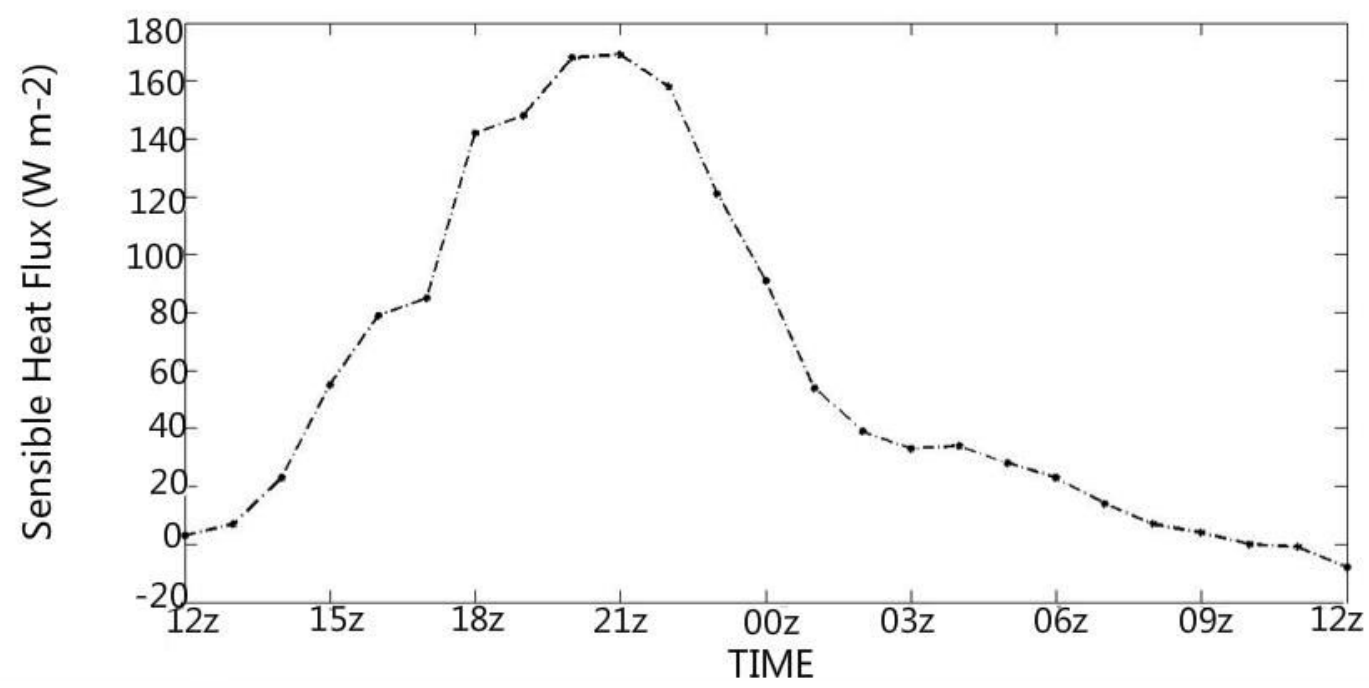

Figure 15: ATDD flux site $\mathrm{C}$ observed 24-h diurnal variation of sensible heat flux $\left(\mathrm{W} \mathrm{m}^{-2}\right)$ in OKC. 


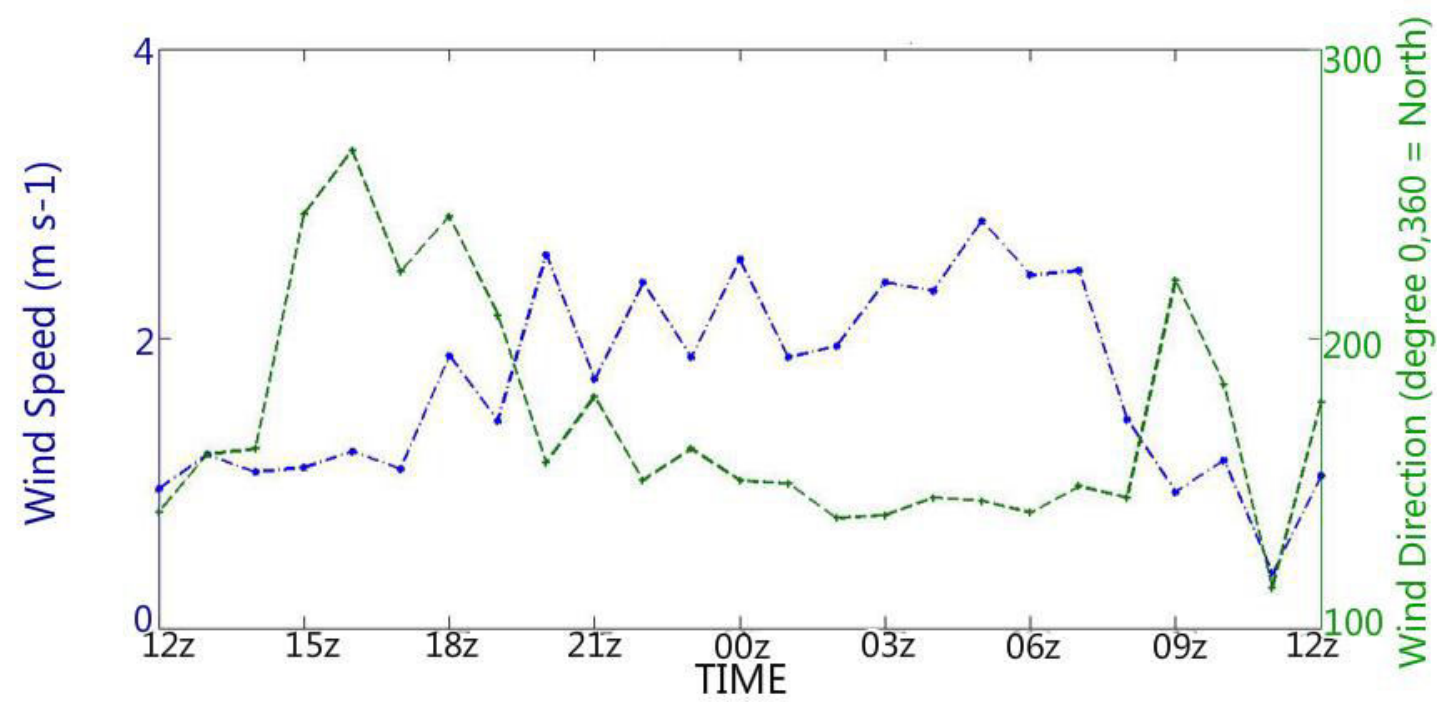

Figure 16: ATDD flux site $\mathrm{C}$ observed 24-h diurnal variation of wind speed and wind direction in OKC.

In conclusion, the ground observations confirmed presence of a UCI effect in OKC.

This unusual phenomenon may be related to several aspects. For example, aerosols are

more prevalent in the atmosphere over the urban regions. In addition, the aerosol's direct

effects, such as scattering and absorption, will reduce surface insolation (Jin and

Shepherd 2010). Moreover, as the building density in OKC is small, tall buildings may

produce a shading effect. In contrast, during daytime in summer, especially at noon, the

nonurban regions are directly exposed to the heat of the sun. Thus, the $\mathrm{T}_{\text {air }}$ observed over

the nonurban area is higher than that for the urban area.

\section{WRF/Single-Layer Urban Canopy Model (SLUCM) Simulation Analysis}

The UHI effect is mainly due to the change of land use type, especially the amount of its urban fractions. Thus, in order to understand the model performance, the 
simulations of UHI variables in OKC are compared to the UHI variables from MODIS observations. First, the land cover map of OKC (Fig. 17a) sourced from the National Land Cover Database 2001 (NLCD 2001, referred to as the NLCD land cover classification legend) is compared with the land cover map simulated from WRF (Fig. 17b). The pink pixels (legend 22), red pixels (legend 23), and dark red pixels (legend 24) in the NLCD land cover map represent the urban regions in OKC. In the modelsimulated land cover map, the black pixels represent the urban regions in OKC based on the USGS 24-category land use categories in Table 6 (http://www2.mmm.ucar.edu/wrf/users/docs/user_guide_V3/users_guide_chap3.htm _Selecting_Between_USGS). By calculating the urban fractions for both land cover maps, much smaller WRF-simulated land use for urban regions in OKC is obtained, with a value of $2 \%$, than its actual condition with an urban fraction of $20 \%$. Such a significant difference in urban fraction may directly lead to UHI deficiencies in the WRF simulation. 

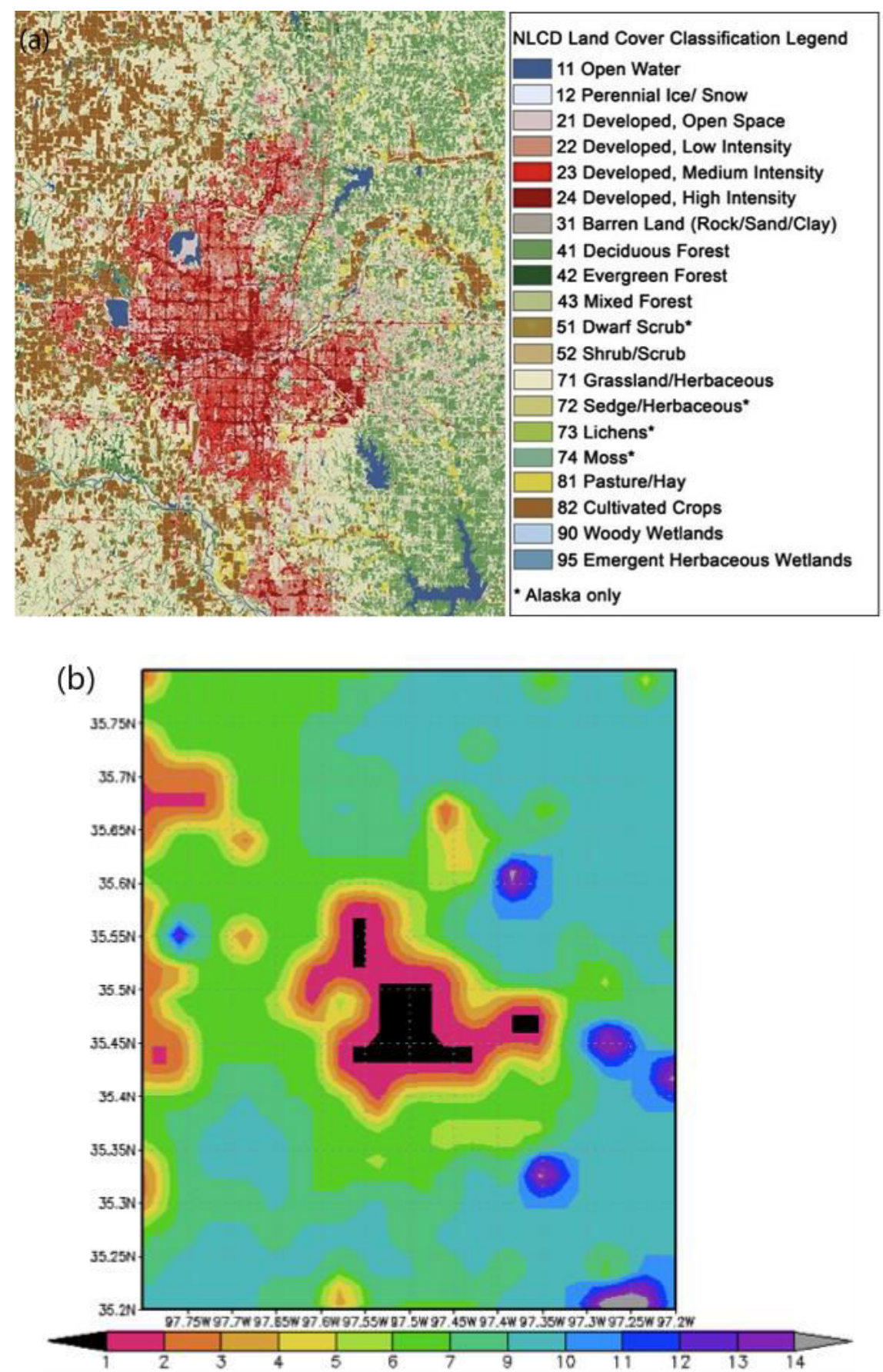

Figure 17: Land use maps for OKC from (a) National Land Cover Database 2001 and (b) WRF/SLUCM simulation. 
TABLE 6: USGS 24-category Land use categories

\begin{tabular}{|c|c|}
\hline Land Use Category & Land Use Description \\
\hline 1 & Urban and Built-up Land \\
\hline 2 & Dryland Cropland and Pasture \\
\hline 3 & Irrigated Cropland and Pasture \\
\hline 4 & Mixed Dryland/Irrigated Cropland and Pasture \\
\hline 5 & Cropland/Grassland Mosaic \\
\hline 6 & Cropland/Woodland Mosaic \\
\hline 7 & Grassland \\
\hline 8 & Shrubland \\
\hline 9 & Mixed Shrubland/Grassland \\
\hline 10 & Savanna \\
\hline 11 & Deciduous Broadleaf Forest \\
\hline 12 & Deciduous Needleleaf Forest \\
\hline 13 & Evergreen Broadleaf \\
\hline 14 & Evergreen Needleleaf \\
\hline 15 & Mixed Forest \\
\hline 16 & Water Bodies \\
\hline 17 & Herbaceous Wetland \\
\hline 18 & Wooden Wetland \\
\hline 19 & Barren or Sparsely Vegetated \\
\hline 20 & Herbaceous Tundra \\
\hline 21 & Wooded Tundra \\
\hline 22 & Mixed Tundra \\
\hline 23 & Bare Ground Tundra \\
\hline 24 & Snow or Ice \\
\hline
\end{tabular}

Both the simulated $\mathrm{T}_{\text {skin }}$ difference $\left(\mathrm{TSK}_{\text {diff }}\right.$, Fig. $\left.18 \mathrm{a}\right)$ and $\mathrm{T}_{\text {air }}$ difference $\left(\mathrm{T} 2_{\text {diff }}\right.$, Fig.

18b) between the sensitive run and the control run at 18 UTC, July 19, 2003 suggest a

UCI effect in OKC for both $\mathrm{T}_{\text {skin }}$ and $\mathrm{T}_{\text {air }}$ fields. The $\mathrm{TSK}_{\text {diff }}$ and $\mathrm{T} 22_{\text {diff }}$ were calculated using the following expressions:

$\mathrm{TSK}_{\text {diff }}=\mathrm{TSK}_{\text {sensitive run }}-\mathrm{TSK}_{\text {control run }}$

$\mathrm{T} 2_{\text {diff }}=\mathrm{T} 2_{\text {sensitive run }}-\mathrm{T} 2_{\text {control run }}$ 
Both figures indicate that the simulated $\mathrm{T}_{\text {skin }}$ with SLUCM is also smaller than the simulated $\mathrm{T}_{\text {skin }}$ without SLUCM for the 2-meter $\mathrm{T}_{\text {air }}$. In addition, the UCI effect is greater on $\mathrm{T}_{\text {air }}$ field (minimum value $=-0.6{ }^{\circ} \mathrm{C}$ ) than on $\mathrm{T}_{\text {skin }}$ field $\left(\right.$ minimum value $=-0.4{ }^{\circ} \mathrm{C}$ ).
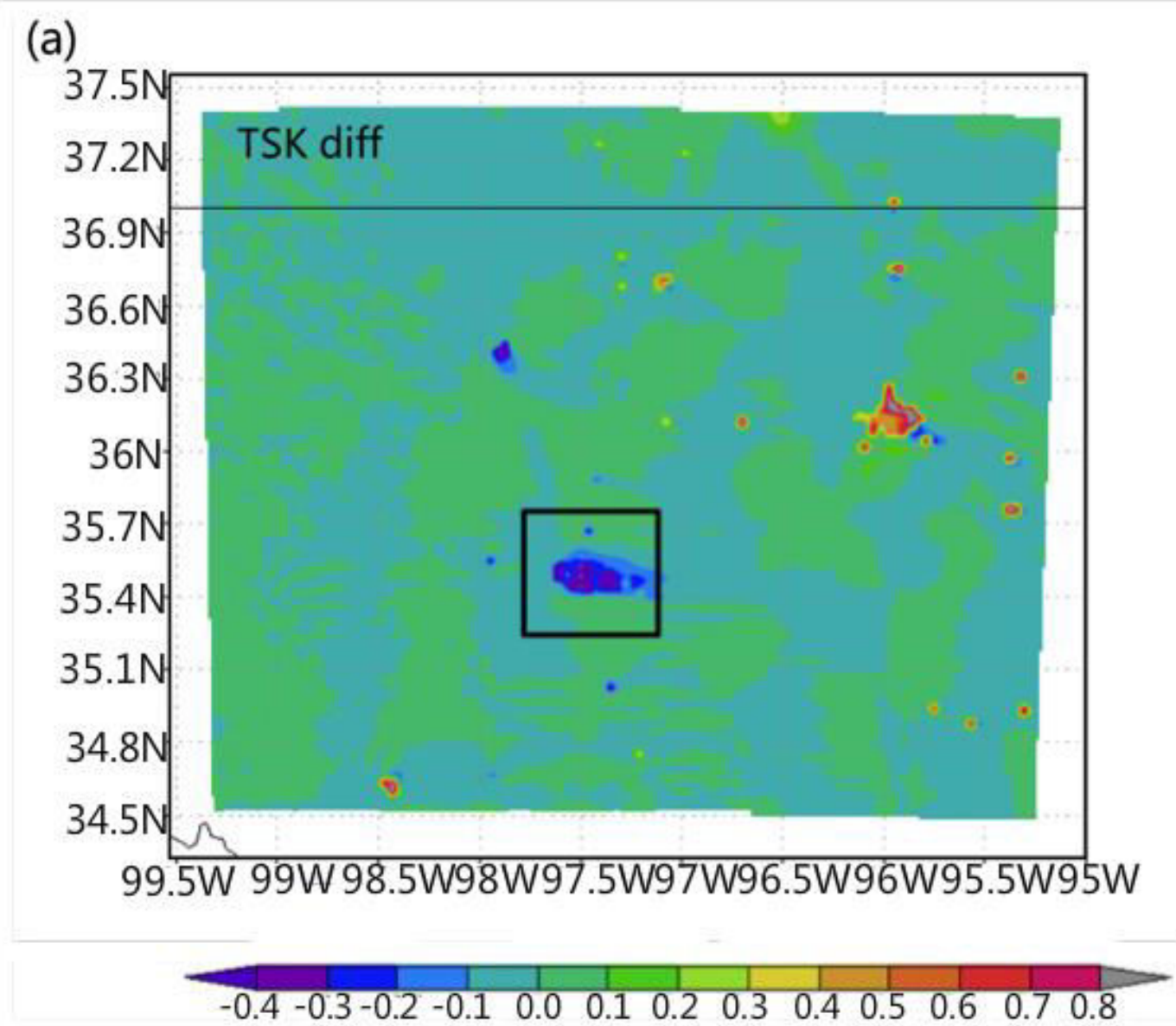


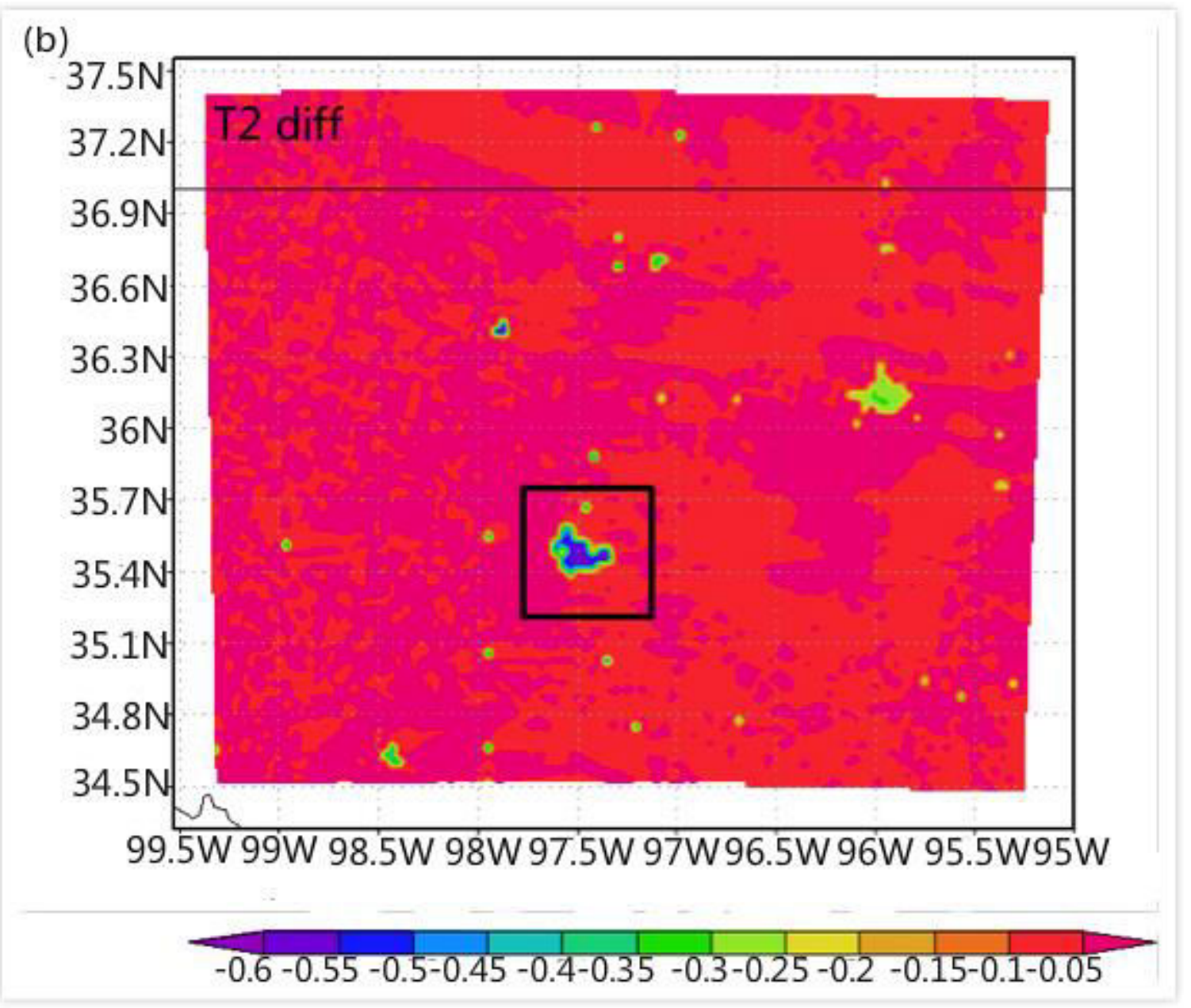

Figure 18: (a) WRF simulated surface temperature difference at 18 UTC, July 19, 2003, in OKC for $\mathrm{T}_{\text {skin }}$ difference (sensitive run - control run). (b) WRF simulated surface temperature difference at 18 UTC, July 19, 2003 in OKC for 2-meter $\mathrm{T}_{\text {air }}$ difference (sensitive run - control run) Temperatures are expressed in $\mathrm{K}$, and $\mathrm{OKC}$ is represented as the rectangle area.

The 24-h simulation of $\mathrm{T}_{\text {skin }}$ began at 1200 UTC (0600 LST), July 19, 2003 and pertains to both the sensitive run and the control run (Fig. 19a). The $\mathrm{T}_{\text {skin }}$ difference between the sensitive run and the control run (Fig. 19b) indicates that, during most of the daytime, the $T_{\text {skin }}$ simulated from the sensitive run are lower than the $T_{\text {skin }}$ simulated from 
the control run. The peak value of $\mathrm{T}_{\text {skin }}$ for the sensitive run is $324.80 \mathrm{~K}$ at $19 \mathrm{UTC}$, and the minimum value is $298.50 \mathrm{~K}$ at $12 \mathrm{UTC}$. On the other hand, for the control run, the peak value of $324.95 \mathrm{~K}$ is obtained at $19 \mathrm{UTC}$, and the minimum value of $298.50 \mathrm{~K}$ is measured at 12 UTC. The peak value of both sensitive and control run occur at 19 UTC because the incoming solar radiation is the strongest at noon (18 UTC) and, as the surface is heated, $\mathrm{T}_{\text {skin }}$ starts increasing. Thus, $\mathrm{T}_{\text {skin }}$ reaches the peak value at $19 \mathrm{UTC}$.

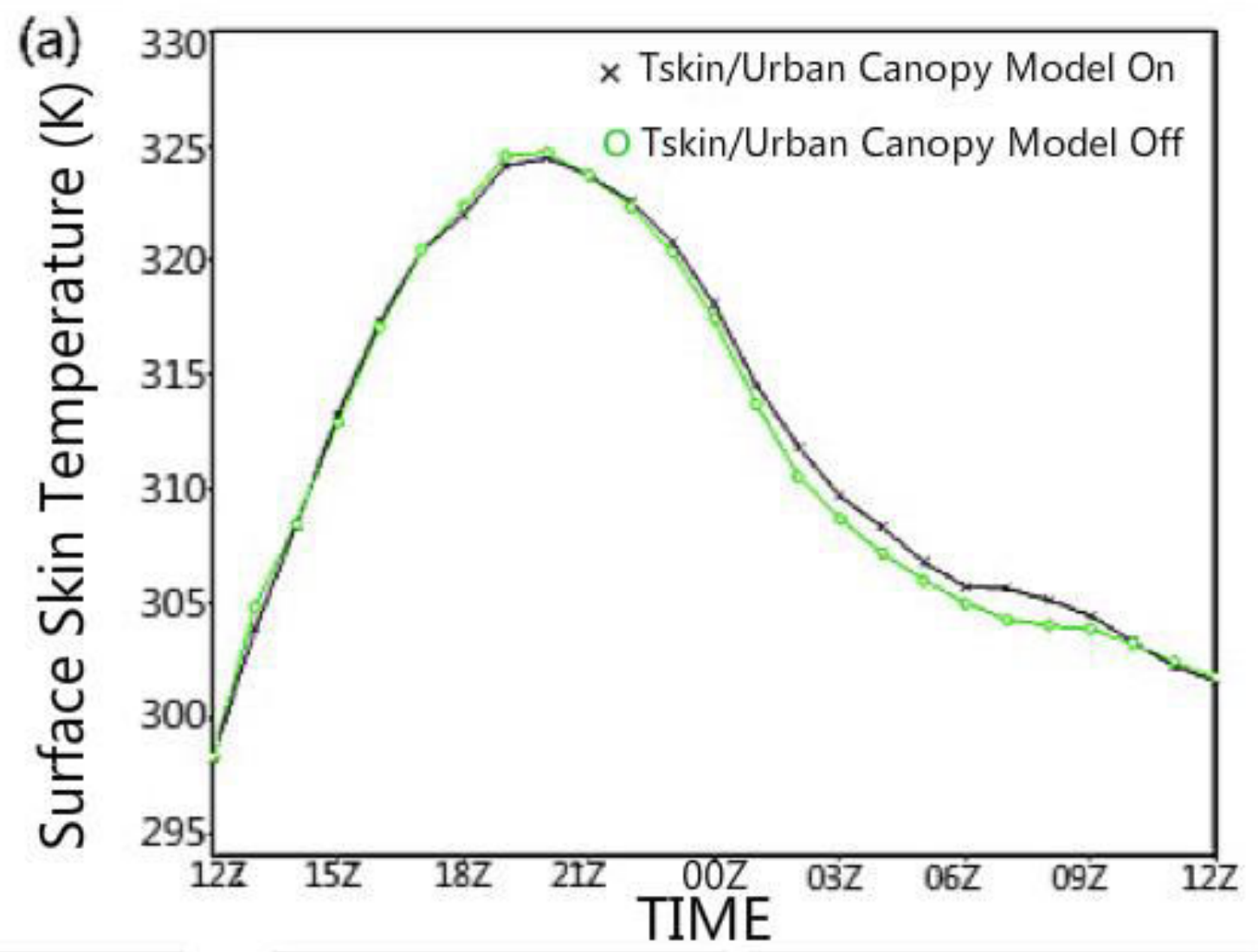


(b)

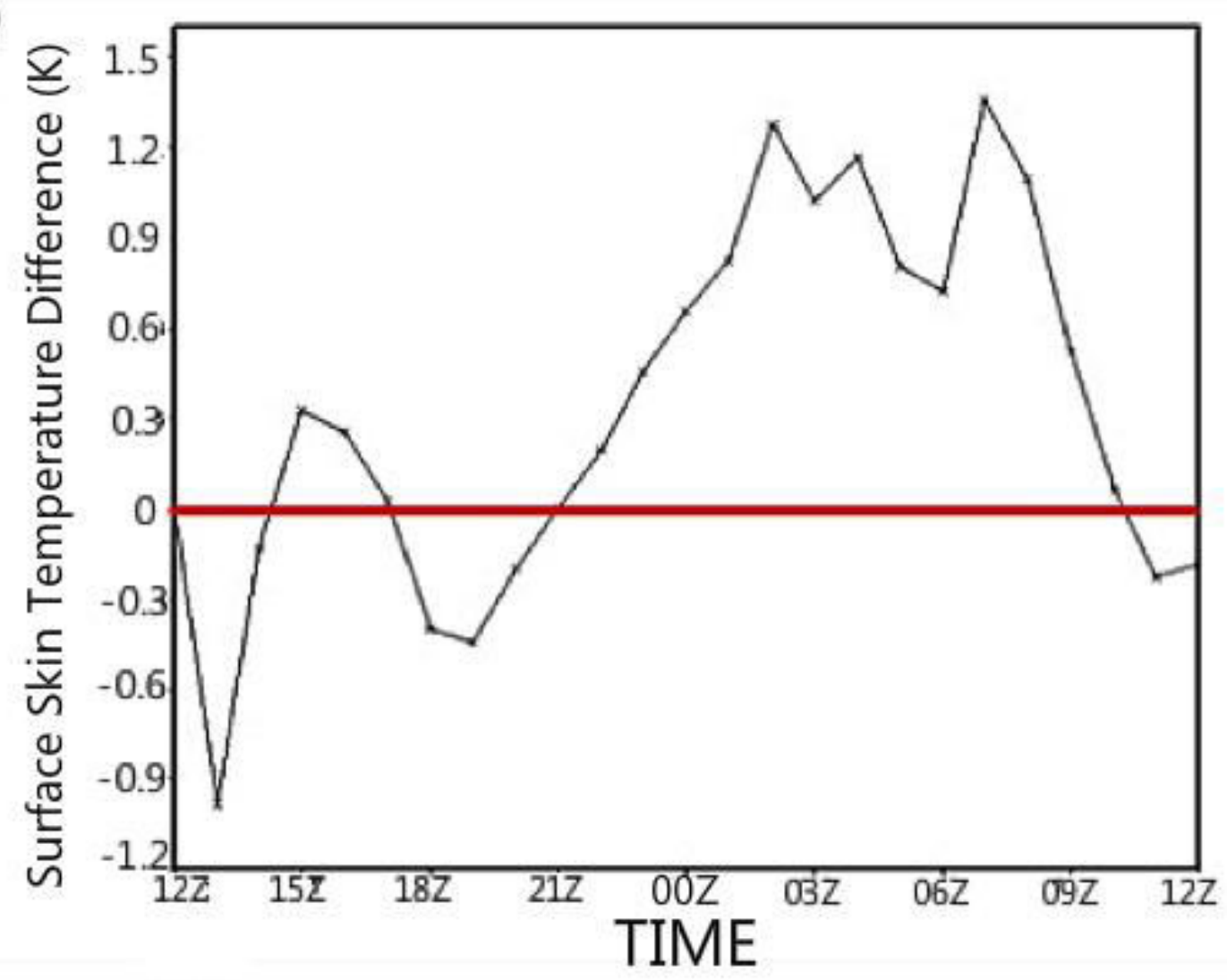

Figure 19: (a) $\mathrm{T}_{\text {skin }}$ (sensitive run vs. control run) in urban regions in $\mathrm{OKC}$, with the green curve representing the simulation of the control run, and the black curve representing the simulation of the sensitive run. (b) $\mathrm{T}_{\text {skin }}$ difference (sensitive run - control run) in urban regions in OKC.

The 24-h WRF/SLUCM simulation of $\mathrm{T}_{\text {skin }}$ for both the urban area and rural area (Fig. 20a) and the $\mathrm{T}_{\text {skin }}$ difference between urban area and rural area (Fig. 20b) in OKC suggest that, during most of the daytime, the $\mathrm{T}_{\text {skin }}$ measurements over the urban regions are lower than those observed over the rural regions in $\mathrm{OKC}$, by about $2 \mathrm{~K}$. The peak value of $\mathrm{T}_{\text {skin }}(325.80 \mathrm{~K})$ over urban regions in OKC was measured at $19 \mathrm{UTC}$, while the minimum $\mathrm{T}_{\text {skin }}(298.0 \mathrm{~K})$ occurred at $12 \mathrm{UTC}$. However, for the $\mathrm{T}_{\text {skin }}$ over the rural regions in OKC, the peak of about $327.8 \mathrm{~K}$ occurred at $19 \mathrm{UTC}$, and its minimum of 
about $296.5 \mathrm{~K}$ was measured at $11 \mathrm{UTC}$. This simulated result is consistent with the UCI effect yielded by the ground observations.

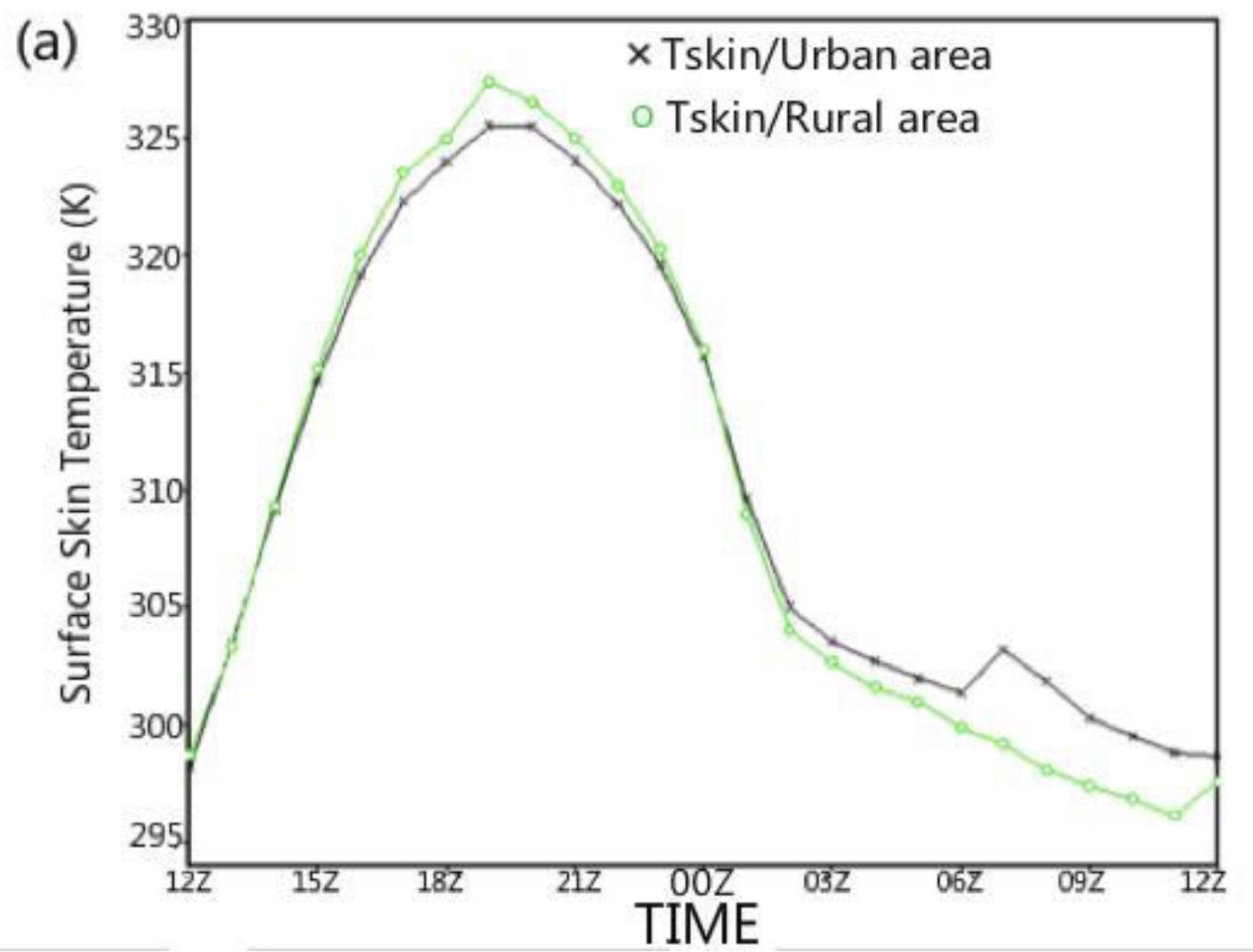




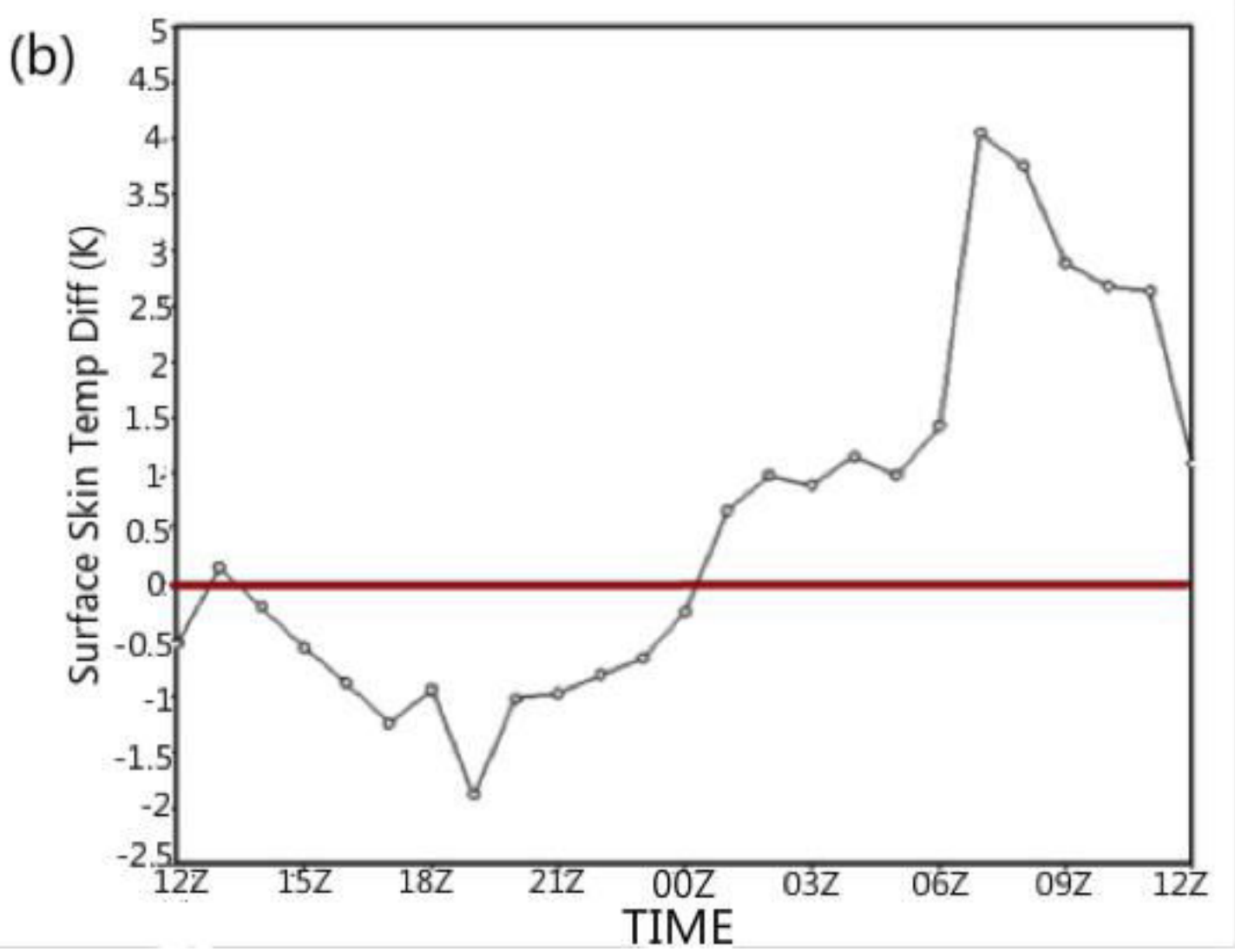

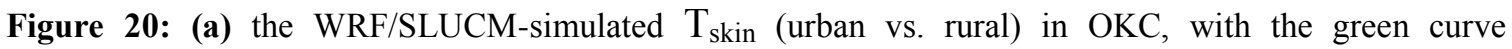
representing the $\mathrm{T}_{\text {skin }}$ over OKC urban area, and the black curve representing the $\mathrm{T}_{\text {skin }}$ over its rural area. (b) the SLUCM-simulated $\mathrm{T}_{\text {skin }}$ difference (urban - rural) in OKC.

During most of the daytime, the wind speeds over urban regions seem higher than those over rural areas. The only exception was the period from 14 UTC to 16 UTC (Fig. 21a), when a peak value of $5 \mathrm{~m} / \mathrm{s}$ was measured at 21 UTC. During nighttime, the wind speeds over urban regions reached values as high as $9 \mathrm{~m} / \mathrm{s}$ at $08 \mathrm{UTC}-11 \mathrm{UTC}$. During most of the daytime, both urban and rural regions experience predominantly southerly winds; however, at 16 UTC, northerly winds were observed. During nighttime, there was an abrupt change at 04 UTC over urban regions, whereby southerly winds were replaced 
by northerly winds. During the 04 UTC - 05 UTC period, the urban regions experienced northerly winds, which subsequently changed to southerly winds. On the other hand, southerly winds were predominant in rural regions; however, northerly winds were recorded at 03 UTC and 06 UTC. Because the wind speeds over urban regions were higher than those affecting the rural regions, this may be one reason for the WRF/SLUCM-simulated UCI effect in OKC, which is consistent with ground observations.

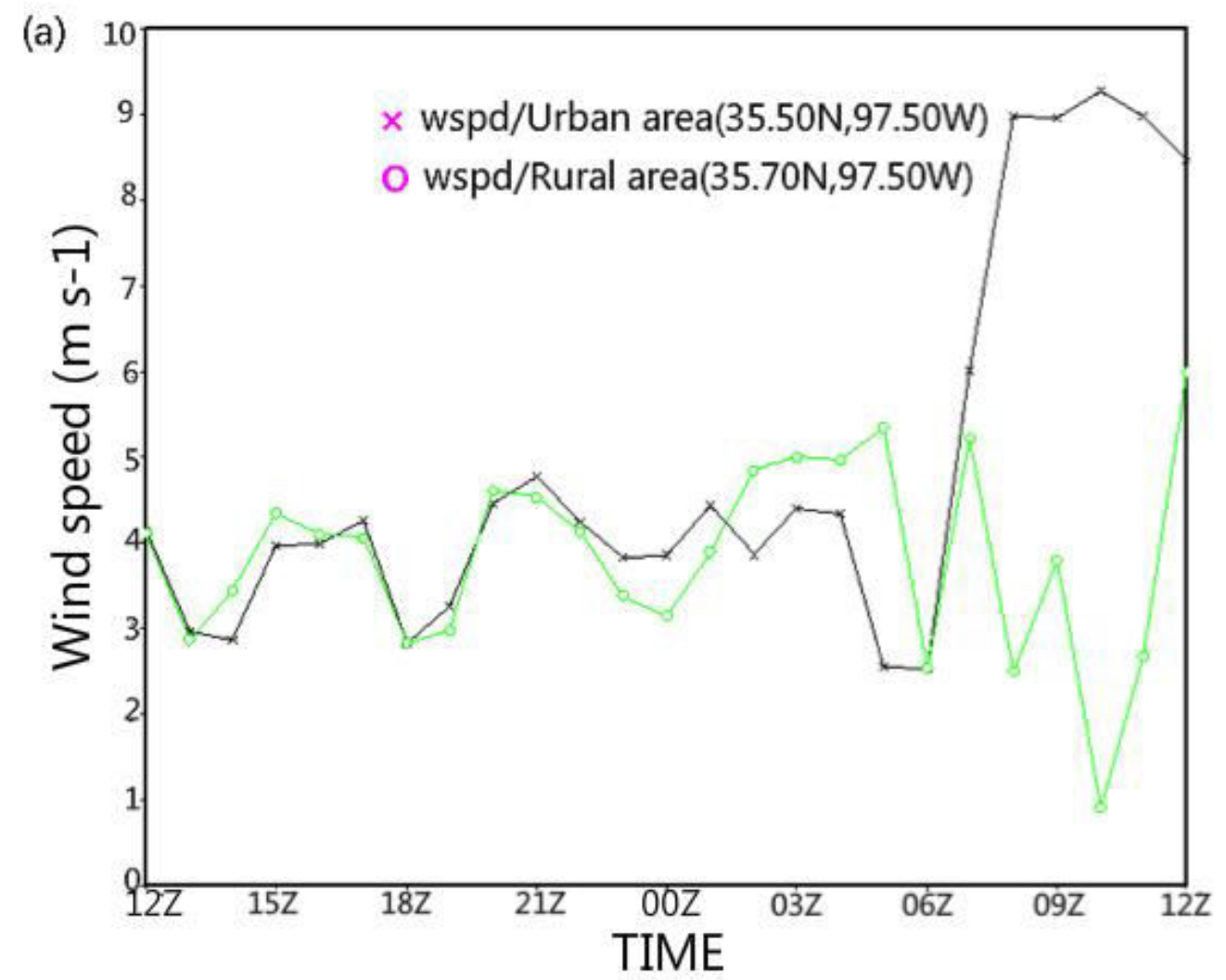




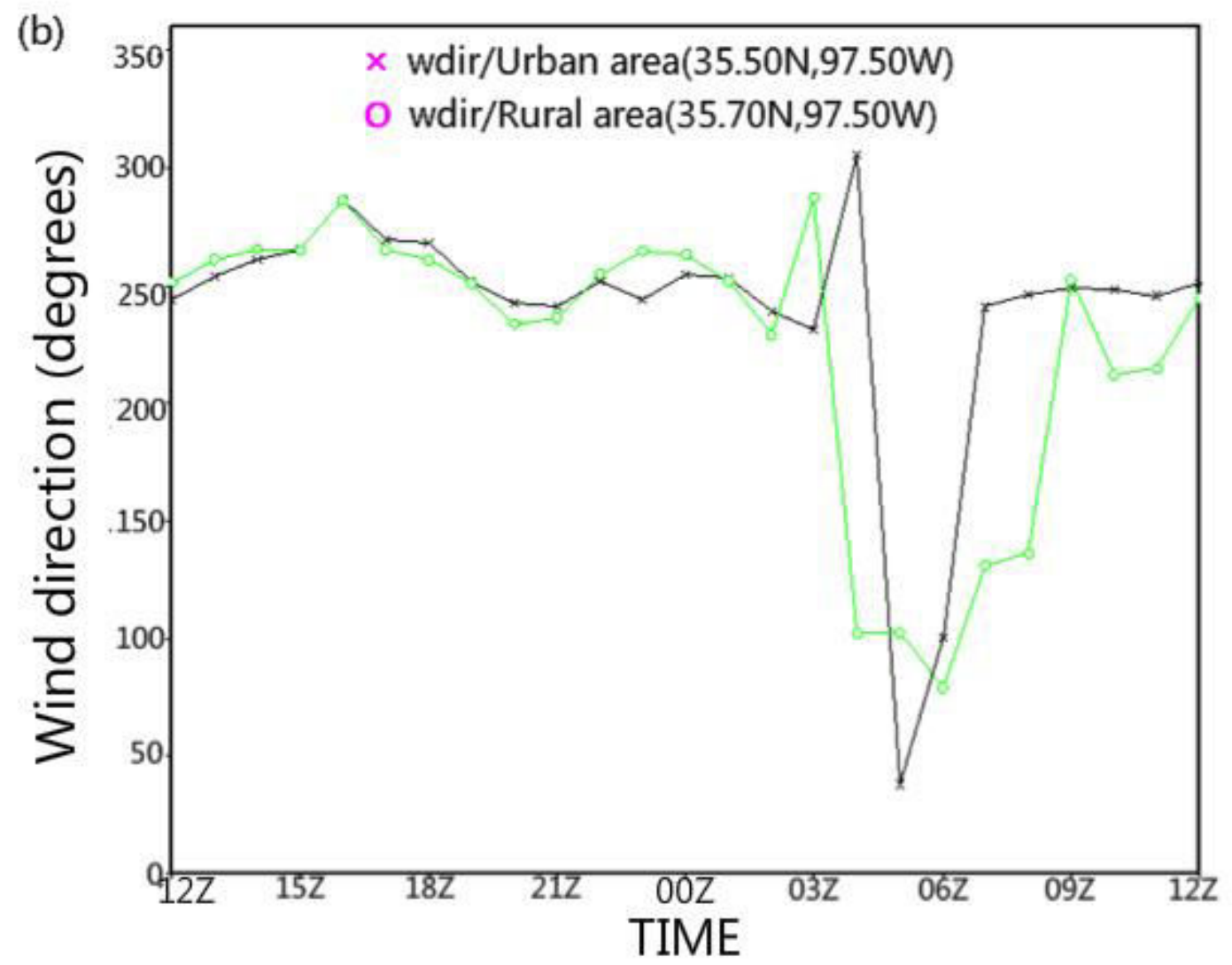

Figure 21: (a) the WRF/SLUCM-simulated wind speed (urban vs. rural) in OKC. The black line shows the wind speeds over the urban area, while the green line shows the wind speeds over the rural area. (b) the WRF/SLUCM-simulated wind direction (urban vs. rural) in OKC. The black line shows the wind directions over the urban area, and the green line shows the wind directions over rural area.

In order to evaluate the sensitivity and accuracy of the WRF/SLUCM simulation, its performance was assessed against the surface observations from the PNNL HOBO stations and the ATDD flux site by comparing the diurnal variations of surface temperatures (Fig. 22). Among those urban surface temperatures, the $\mathrm{T}_{\text {skin }}$ (TSK, Fig. 22) has the largest diurnal amplitude, while the ground-observed 2-meter $\mathrm{T}_{\text {air }}\left(\mathrm{T}_{2}\right.$, Fig. 22) has 
the smallest range of diurnal variation. During most of the daytime, the model-simulated 2-meter $\mathrm{T}_{\text {air }}$ are higher than the ground-observed 2-meter $\mathrm{T}_{\text {air. }}$ The difference between $\mathrm{T}_{\text {skin }}$ and $\mathrm{T}_{\text {air }}$ from Fig. 22 demonstrates that it depends strongly on diurnal variations. During daytime, the $\mathrm{T}_{\text {skin }}$ is greater than $\mathrm{T}_{\text {air }}$ because the incoming solar radiation warms up the "skin" of the surface first. However, during nighttime, the $\mathrm{T}_{\text {skin }}$ is generally lower than $\mathrm{T}_{\text {air }}(\mathrm{Jin}$ and Dickinson 1997).

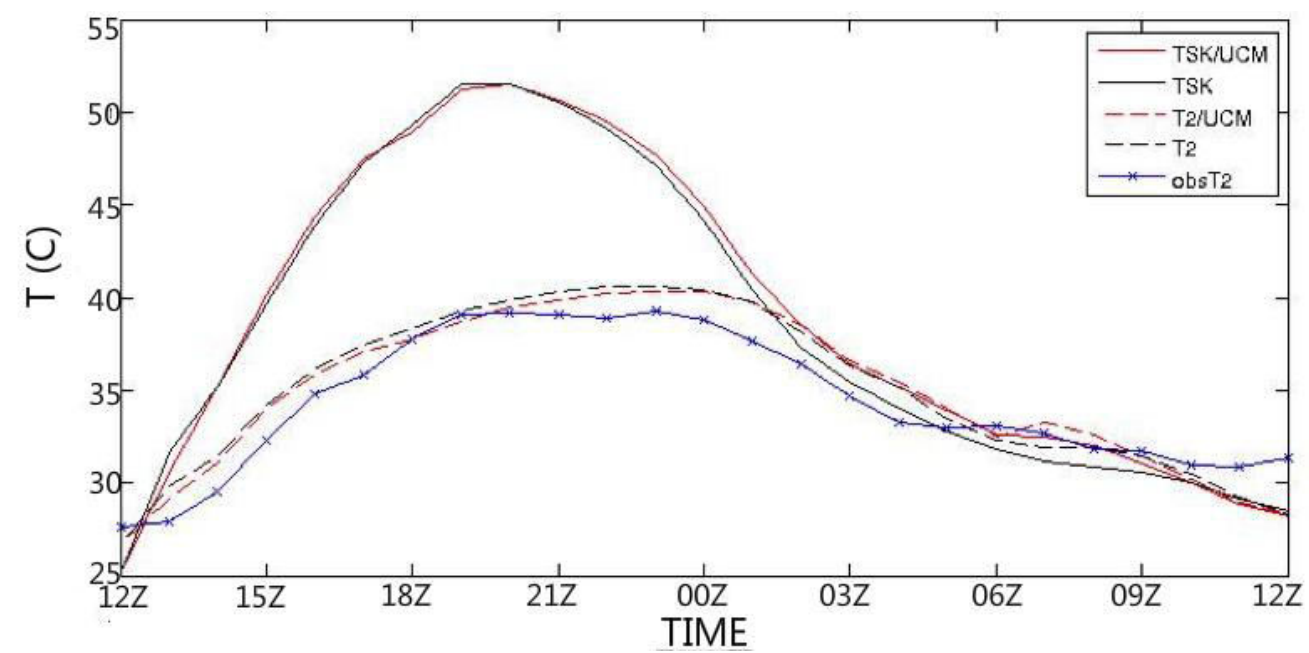

Figure 22: WRF-simulated TSK, $\mathrm{T}_{2}$ and ground-observed $\mathrm{T}_{2}$. The red solid line represents the modelsimulated TSK with SLUCM, the black solid line represents the model-simulated TSK without SLUCM, the red dashed line shows the model-simulated $\mathrm{T}_{2}$ with SLUCM, the black dashed line shows the modelsimulated $\mathrm{T}_{2}$ without SLUCM, and the blue line represents the ground-observed $\mathrm{T}_{2}$ from PNNL HOBO station 9.

Energy flux and the wind properties obtained by the WRF/SLUCM simulations and ground observations were also compared. The findings reveal that, in $\mathrm{OKC}$, the 
simulated downward shortwave radiation is higher than the observed one during daytime (Fig. 23a), while the observed net radiation is much higher than the WRF/SLCUM simulations during daytime (Fig. 23b), and is lower during nighttime. The net radiation refers to the total amount of heat energy that cannot escape from the top of the atmosphere and back into space, and is simply calculated as the difference between incoming solar radiation and outgoing IR. Therefore, higher buildings and areas characterized by greater building density will trap more net radiation in the Earth system. Consequently, the difference in the building height and building density used in the simulation and the actual conditions may be one of the reasons behind this large difference in net radiation. As previously calculated, the urban fraction in the WRF simulation is only about $2 \%$, which is much smaller than the $20 \%$ calculated using the NLCD 2001 data for OKC. 

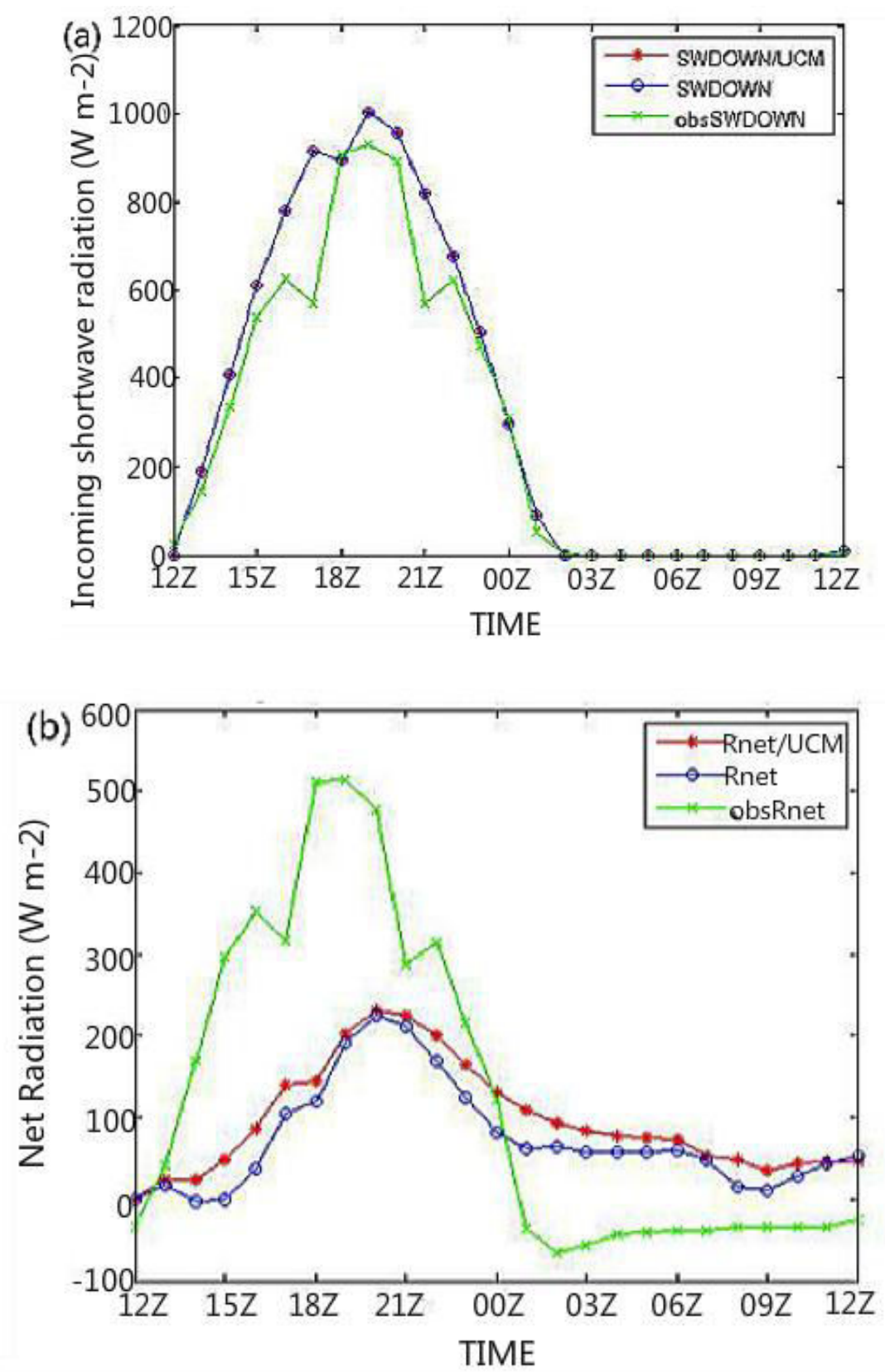

Figure 23: (a) the WRF-simulated downward shortwave radiation and ground-observed downward shortwave radiation in OKC (b): the WRF-simulated net radiation and ground-observed net radiation in OKC. 
Comparisons of wind speeds and wind directions between ground observations and WRF/SLUCM simulations show that the simulated wind speeds are much higher than observed (Fig. 24a), especially from 07 UTC to 12 UTC, July 20, 2003. In addition, the maximum value of simulated wind speed is greater than the observed wind speed by approximately $6.5-6.8 \mathrm{~m} / \mathrm{s}$, and the minimum simulated wind speed is greater than the observed wind speed by approximately $1.6-1.9 \mathrm{~m} / \mathrm{s}$. The wind direction analysis revealed that, based on the observed results, the OKC experiences southerly winds from 12 UTC, July 19 to 12 UTC, July 20, 2003, while the simulated produce a large variation of wind direction, where southerly winds suddenly shift to northerly winds between 03 UTC to 06 UTC July 20.

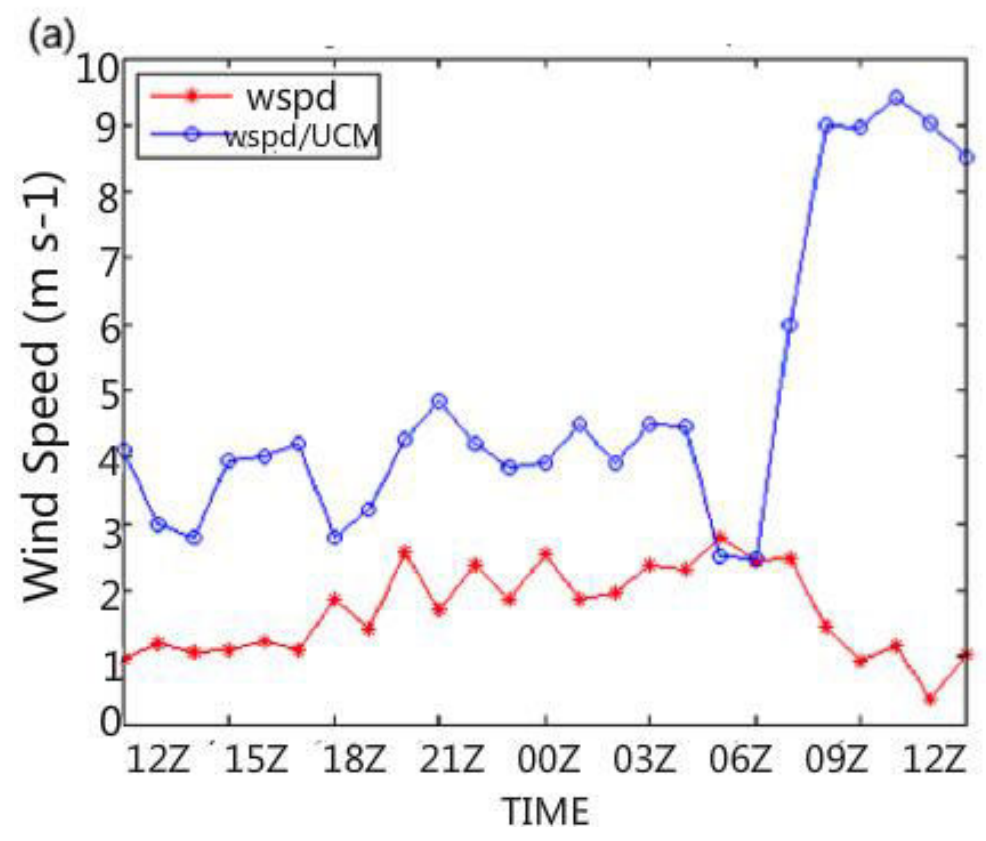




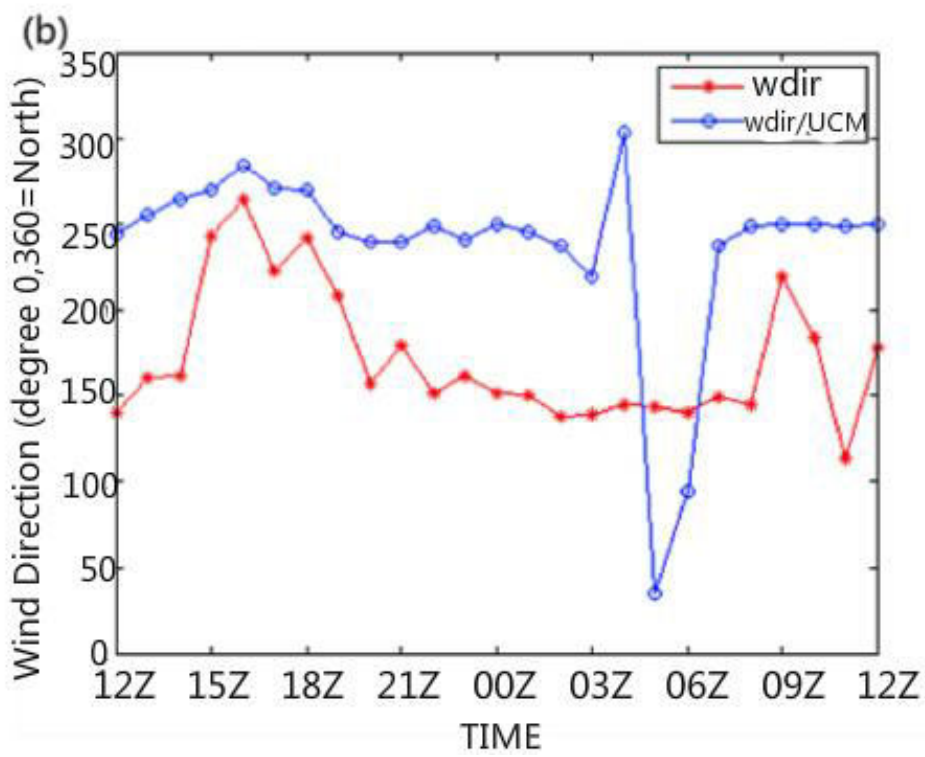

Figure 24: 24-h diurnal variation of WRF/SLUCM simulated and ground observed (a) wind speed (m/s), (b) wind direction (degree $0,360=$ North) in OKC.

In conclusion, the coupled WRF/Noah/SLUCM modeling system was able to reproduce the diurnal variation of surface temperatures and energy flux reasonably well. In addition, it also simulated the UCI effect in OKC during summer; however, it failed to accurately capture the influences of cities on winds, energy flux, and temperatures.

\section{Conclusions}

In this study, the UHI effect (mainly in OKC) was examined by using satellite and ground observations, along with coupled WRF/Noah/Single-Layer Urban Canopy Model simulations. Three major results of this investigation are discussed below. 
First, an urban area is a highly heterogeneous environment and different cities may have different types of urban land covers different geometric conditions, and different population densities. As a result, the UHI effect differs between cities such as OKC and Xi'an City, although both are inland cities at the same latitude. Satellite retrieval captured the UHI effect for both cities. In Xi'an City, the UHI effect was stronger than in $\mathrm{OKC}$, suggesting that the population density and city size are important factors in determining the UHI effect intensity, although the area of the urban region in Xi'an City is smaller than that in OKC.

Second, based on the definition of the UHI effect, it is clear that tall buildings and other urban surface materials can retain heat energy, thus resulting in higher surface temperatures in urban areas relative to nonurban areas. Furthermore, UHI values depend on building height and density. When both of these factors are smaller, the shading buildings provide may reduce the surface temperatures, as shown in ground observations, where a significant UCI effect occurred during summer daytime, especially at noon in OKC. This result further illustrates that the $\mathrm{T}_{\text {skin }}$ and $\mathrm{T}_{\text {air }}$ fields may produce different UHI signal, as the satellite observation of the $\mathrm{T}_{\text {skin }}$ in OKC showed a good UHI effect, while the ground observation of $\mathrm{T}_{\text {air }}$ indicated a significant $\mathrm{UCI}$ effect. 
Third, the coupled WRF/Noah/SLUCM modeling system can simulate the signal of the UHI effect, although its intensity and duration remain problematic. Nevertheless, a main issue affecting WRF urban simulation is that the default settings in the USGS 24category land use categories are outdated for many cities. For instance, the simulated urban fraction for $\mathrm{OKC}$ is only about $2 \%$, while its actual value is about $20 \%$, yielded by NLCD 2001.

In addition, the coupled WRF/Noah/SLCUM model reproduces the UCI effect during summer daytime in $\mathrm{OKC}$, which was consistent with the ground observations. However, it failed to accurately capture the influences of cities on prevalent atmospheric motions, such as wind speed, wind direction, and energy flux.

This study has a broad impact because it combined satellite observations, ground observations, and WRF model simulations, enhancing the current understanding of the UHI effect. In addition, both ground observations and WRF/SLUCM simulations revealed an unusual phenomenon of UCI effects in OKC during daytime in summer. Finally, an update of the default USGS 24-category land use categories could yield significant improvements in the quality of WRF/SLUCM simulation output, as the simulated urban regions for many cities are presently outdated, reducing the accuracy of UHI simulation. 
The present study can be enhanced in several ways. First, the WRF/SLUCM

simulation on Xi' an City can be applied on a case of a city with smaller urban regions, but larger building density and population density, and the sensitivity of the WRF/SLUCM simulation can be evaluated. A comparison of the simulated UHI effect between Xi' an and OKC can also be performed in future studies. In addition, it would be useful to replace the default USGS 24-category land use categories by creating an urban fraction field from NLCD data for OKC. This forcing could be input into the WRF/SLUCM simulation when analyzing the UHI effect in OKC. It is possible that the $\mathrm{T}_{\text {skin }}$ difference between urban regions and rural regions in $\mathrm{OKC}$ could be much greater, and the UCI effect could be more significant. 


\section{References}

Allwine, K. J., and J. E. Flaherty, 2006: Joint Urban 2003: Study Overview and Instrument Locations. PNNL- 15967.

Arnfield, A. J., 2003: Two decades of urban climate research: A review of turbulence, exchanges of energy and water, and the urban heat island. Int. J. Clim., 23, 1-26.

Chen, F., H. Kusaka, and R. Bornstein, 2011: The integrated WRF/urban modeling system: development, evaluation, and applications to urban environmental problems. Int. J. Climatol., 31, 273-288.

Chin, H.-N. S., M. J. Leach, G. A. Sugiyama, J. M. Leone, H. Walker, J. S. Nasstrom, and M. J. Brown, 2005: Evaluation of an urban canopy parameterization in a mesoscale model using VTMX and URBAN 2000 data. Mon. Wea. Rev., 133, 20432068.

Coutts, A. M., J. Beringer, and N. J. Tapper, 2007: Impact of increasing urban density on local climate: Spatial and temporal variation in the surface energy balance in Melbourne, Australia. J. Appl. Meteor. Climatol., 46, 477-493.

Grimmond, C. S. B., and T. R. Oke, 1995: Comparison of heat fluxes from summertime observations in the suburbs of four North American cities. J. Appl. Meteorol., 34, 873-889.

Hamdi, R., and H. Van de Vyver, 2011: Estimating urban heat island effects on nearsurface air temperature records of Uccle (Brussels, Belgium): an observational and modeling study. Adv. Sci. Res., 6, 27-34.

Holt, T., and J. Pullen, 2007: Urban canopy modeling of the New York City metropolitan area: A comparison and validation of single- and multilayer parameterizations. Mon. Wea. Rev., 135, 1906-1930.

Huang, L., H. Huang, D. Xiang, J. Zhu, and J. Li, 2007: The diurnal change of air temperature in four types of land cover and urban heat island effect in Nanjing, China (in Chinese). Ecology and Environment, 16, 1411-1420.

Jin, M., R. E. Dickinson, and A. M. Vogelmann, 1997: A Comparison of CCM2/BATS 
Skin Temperature and Surface-Air Temperature with Satellite and Surface Observations. J. Climate, 10, 1505-1524.

Jin, M., 2000: Interpolation of surface radiation temperature measured from polar orbiting satellites to a diurnal cycle. Part 2: Cloudy-pixel Treatment. J. Geophys. Res., 105, 4061-4076.

_ 2004: Analysis of Skin Temperature Variations Using Long-Duration AVHRR Observations. Bull. Am. Met. Soc., 85, No. 4, 587-600.

, and R. E. Dickinson, 1999: Interpolation of surface radiation temperature measured from polar orbiting satellites to a diurnal cycle. Part 1: Without clouds. $J$. Geophys. Res., 104, 2105- 2116.

— and 2005: The footprint of urban areas on global climate as characterized by MODIS. J. Climate, 18, 1551-1565.

$\longrightarrow$, and 2010: Land surface skin temperature climatology: benefitting from the strengths of satellite observations. Environ. Res. Lett., 5,044004.

, and J. M. Shepherd, 2008: Aerosol relationships to warm season clouds and rainfall at monthly scales over east China: Urban land versus ocean. J. Geophys. Res., 113, D24S90, doi:10.1029/2008JD010276.

, W. Kessomkiat, and G. Pereira, 2011: Satellite-Observed Urbanization Characters in Shanghai, China: Aerosols, Urban Heat Island Effect, and Land-Atmosphere Interactions. Remote Sensing, 3, 83-99.

, and T. Mullens, 2012: Land-Biosphere-Atmosphere Interactions over Tibetan Plateau from MODIS Observations. Environ. Res. Lett., 7, 014003.

Jones, P. D., P. M. Kelly, and C. M. Goodess, 1989: The effect of urban warming on the northern hemisphere temperature average. J. Climate, 2, 285-290.

Kim, Y.-H., and J.-J. Baik, 2005: Spatial and temporal structure of the urban heat island in Seoul. J. Appl. Meteorol., 44, 591-605.

King, M. D., Y. J. Kaufman, W. P. Menzel, and D. Tanre, 1992: Remote sensing of cloud, 
aerosol, and water vapor properties from the Moderate Resolution Imaging Spectrometer (MODIS). IEEE. Trans. Geosci. Remote Sens., 30, 2-27.

Kusaka, H., and F. Kimura, 2004a: Coupling a single-layer urban canopy model with a simple atmospheric model: Impact on urban heat island simulation for an idealized case. J. Meteor. Soc. Japan, 82, 67-80.

, Konda, Y. Kikegawa, and F. Kimura, 2001: A simple single-layer urban canopy model for atmospheric models: Comparison with multi-layer and slab models. Bound.-Layer Meteor., 101, 329-358.

, and Coauthors, 2003: Cloud and aerosol properties, precipitable water, and profiles of temperature and humidity from MODIS. IEEE Trans. Geosci. Remote Sens., 41, 442-458.

Landsberg, H. E., 1981: The Urban Climate. Academic Press, New York, 275 pp.

Martilli, A., 2002: Numerical study of urban impact on boundary layer structure: Sensitivity to wind speed, urban morphology, and rural soil moisture. J. Appl. Meteorol., 41, 1247-1266.

Masson, V., 2000: A physically-based scheme for the urban energy budget in atmospheric models. Bound.-Layer Meteor., 94, 357-397.

Miao, S., F. Chen, M. A. LeMone, M. Tewari, Q. Li, and Y. Wang, 2009: An observational and modeling study of characteristics of urban heat island and boundary layer structures in Beijing. J. Appl. Meteor. Climatol., 48, 484-501.

Montavez, J. P., A. Rodriguez, and J. I. Jimenez, 2000: A study of the urban heat island of Granada. Int. J. Climatol., 20, 899-911.

Oke, T. R., 1981: Canyon geometry and the nocturnal Urban Heat Island. Int. J.

Climatol., 10, 237-245.

, 1982: The energetic basis of the Urban Heat Island. Quart. J. R. Met. Soc., 108, $1-24$.

, 1987: Boundary Layer Climates. Routledge, London, 435 pp. 
, G. T. Johnson, D. G. Steyn, and I. D. Watson, 1991: Simulation of surface Urban Heat Island. Bound. Layer Meteorol., 56, 339-358.

, G. Zeuner, and E. Jauregui, 1992: The surface energy balance in Mexico City. Atmos. Environ., 26B, 433-444.

Ren, G., Y. Zhou, Z. Chu, J. Zhou, A. Zhang, J. Guo, and X. Liu, 2008: Urbanization effects on observed surface air temperature trends in north China. J. Climate, 21, $1333-1348$.

Shepherd, J. M., R. Showstack, and M. Jin, 2007: Linkages between the built urban environment and earth's climate system. Eos, 85, 227-228.

Shou, Y. X., and D. L. Zhang, 2010: Impact of environment flows on the daytime urban boundary layer structures over the Baltimore metropolitan region. Atmos. Sci. Lett., 11, 1-6.

Steven H., E. Marciotto, and R. Britter, 2011: Urban Energy Fluxes in Built-Up Downtown Areas and Variations across the Urban Area, for Use in Dispersion Models. J. Appl. Meteor. Climatol., 50, 1341-1353.

Tewari, M., and F. Chen, 2011: A Study of the Urban Boundary Layer Using Different Urban Parameterizations and High-Resolution Urban Canopy Parameters with WRF. J. Appl. Meteor. Climatol., 50, 1107-1128.

Trusilova, K., M. Jung, and G. Churkina, 2009: On climate impacts of a potential expansion of urban land in Europe. J. Appl. Meteor. Climatol., 48, 1971-1980.

Yang, B., 2012: Simulation of Urban Climate with High-Resolution WRF Model: A case Study in Nanjing, China. Asia-Pacific J. Atmos. Sci., 48, 227-241.

Yow, D. M., 2007: Urban heat islands: observations, impacts, and adaptation. Geography Compass, 1, 1227-1251. 
APPENDIX: ACRONYMS

$\begin{array}{ll}\text { UHI } & \text { Urban Heat Island } \\ \text { UCI } & \text { Urban Cooling Island } \\ \text { MODIS } & \text { Moderate Resolution Imaging Spectroradiometer } \\ \text { JU2003 } & \text { Joint Urban 2003 } \\ \text { PNNL } & \text { Pacific Northwest National Laboratory } \\ \text { ATDD } & \text { Atmospheric Turbulence and Diffusion Division } \\ \text { CBD } & \text { Central Business District } \\ \text { WRF } & \text { Weather Research and Forecasting } \\ \text { SLUCM } & \text { Single-Layer Urban Canopy Model } \\ \text { OKC } & \text { Oklahoma City } \\ T_{\text {skin }} & \text { Skin Temperature } \\ \mathrm{T}_{\text {air }} & \text { Air Temperature } \\ \text { IR } & \text { Infrared Radiation }\end{array}$

